\title{
Seascape ecology: identifying research priorities for an emerging ocean sustainability science
}

\author{
S. J. Pittman ${ }^{1,2, *}$, K. L. Yates ${ }^{3}$, P. J. Bouchet ${ }^{4,5}$, D. Alvarez-Berastegui ${ }^{6}$, S. Andréfouët ${ }^{7}$, \\ S. S. Bell ${ }^{8}$, C. Berkström ${ }^{9,10}$, C. Boström ${ }^{11}$, C. J. Brown ${ }^{12}$, R. M. Connolly ${ }^{13}$, \\ R. Devillers ${ }^{14}$, D. Eggleston ${ }^{15}{ }^{\prime}$, B. L. Gilby ${ }^{16}$, M. Gullström ${ }^{17}{ }^{17}$ B. S. Halpern ${ }^{18,19}$, \\ M. Hidalgo ${ }^{20}$, D. Holstein ${ }^{21}$, K. Hovel ${ }^{22}$, F. Huettmann ${ }^{23}$, E. L. Jackson ${ }^{24}$, W. R. James ${ }^{25}$, \\ J. B. Kellner ${ }^{26}$, C. Y. Kot ${ }^{27}$, V. Lecours ${ }^{28}$, C. Lepczyk ${ }^{29}$, I. Nagelkerken ${ }^{30}$, J. Nelson ${ }^{21}$, \\ A. D. Olds ${ }^{16}$, R. O. Santos ${ }^{31}$, K. L. Scales ${ }^{16}$, D. C. Schneider ${ }^{32}$, H. T. Schilling ${ }^{33,34}$,
} C. Simenstad ${ }^{35}$, I. M. Suthers ${ }^{33,34}$, E. A. Treml ${ }^{36}$, L. M. Wedding ${ }^{1}$, P. Yates ${ }^{34,37}$, M. Young ${ }^{36}$

${ }^{1}$ Oxford Seascape Ecology Lab, School of Geography and the Environment, University of Oxford, Oxford OX1 3QY, UK ${ }^{2}$ Project Seascape CIC, Plymouth PL2 1RP, UK

Full author addresses are given in the Appendix

ABSTRACT: Seascape ecology, the marine-centric counterpart to landscape ecology, is rapidly emerging as an interdisciplinary and spatially explicit ecological science with relevance to marine management, biodiversity conservation, and restoration. While important progress in this field has been made in the past decade, there has been no coherent prioritisation of key research questions to help set the future research agenda for seascape ecology. We used a 2-stage modified Delphi method to solicit applied research questions from academic experts in seascape ecology and then asked respondents to identify priority questions across 9 interrelated research themes using 2 rounds of selection. We also invited senior management/conservation practitioners to prioritise the same research questions. Analyses highlighted congruence and discrepancies in perceived priorities for applied research. Themes related to both ecological concepts and management practice, and those identified as priorities include seascape change, seascape connectivity, spatial and temporal scale, ecosystem-based management, and emerging technologies and metrics. Highestpriority questions (upper tercile) received $50 \%$ agreement between respondent groups, and lowest priorities (lower tercile) received 58\% agreement. Across all 3 priority tiers, 36 of the 55 questions were within a $\pm 10 \%$ band of agreement. We present the most important applied research questions as determined by the proportion of votes received. For each theme, we provide a synthesis of the research challenges and the potential role of seascape ecology. These priority questions and themes serve as a roadmap for advancing applied seascape ecology during, and beyond, the UN Decade of Ocean Science for Sustainable Development (2021-2030).

${ }^{*}$ Corresponding author: sjpittman@gmail.com

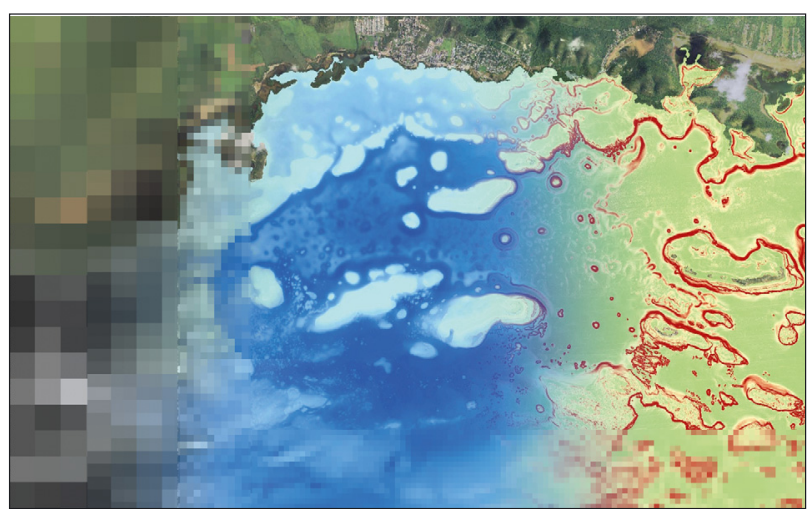

To understand why spatial patterns matter, seascape ecology works with maps such as this seafloor terrain showing the surface complexity of coral reef ecosystems at multiple spatial scales

Image: Simon J. Pittman

KEY WORDS: Research priorities · Ecosystem-based management $\cdot$ Sustainability science $\cdot$ Connectivity $\cdot$ Restoration $\cdot$ Spatial patterns

\section{INTRODUCTION}

Seascapes are complex ocean spaces, shaped by dynamic and interconnected patterns and processes operating across a range of spatial and temporal scales (Steele 1989, Levin 1992, Pittman 2018a). Rapid advances in geospatial technologies and the proliferation of sensors, both above and below the ocean surface, have revealed intricate and scientifically intriguing

() The authors 2021. Open Access under Creative Commons by Attribution Licence. Use, distribution and reproduction are unrestricted. Authors and original publication must be credited. 
ecological patterns and processes (Thrush et al. 1997, Schneider 2001, Boström et al. 2011), some of which are the result of human activities (Bishop et al. 2017, Halpern et al. 2019). Despite progress in the collecting, mapping, and sharing of ocean data, the gap between technological advancement and our ability to generate ecological insights for marine management and conservation practice remains substantial (Borja et al. 2020, Claudet et al. 2020). For instance, fundamental gaps exist in our understanding of the multidimensional spatial structure in the sea (Boström et al. 2011, Pittman 2018a, D'Urban-Jackson et al. 2020), and the implications for planetary health and human wellbeing (Claudet et al. 2020). A deeper understanding of the multi-scale linkages between ecological structure, function, and change can better support the design of whole-system strategies for biodiversity preservation and reduce the uncertainty around the consequences of human activity. For example, in the design and evaluation of marine protected areas (MPAs) and habitat restoration, it is important to understand the influence of spatial context, configuration, and connectivity, and to consider the effects of scale (GarcíaCharton et al. 2004, Huntington et al. 2010, Olds et al. 2016, Gilby et al. 2018b, Proudfoot et al. 2020).

Questions focussed on these crucial, overlooked, and typically complex spatial variables can be addressed through the integrative, multi-scale and pattern-oriented conceptual framework of landscape ecology (Turner 1989, Ray 1991, Wedding et al. 2011, Pittman 2018b). Landscape ecologists seek to understand the causes and consequences of spatial complexity (i.e. process-pattern linkages) through the application of pattern-oriented concepts, tools, and techniques (Turner 2005, Wedding et al. 2011, Wu 2013). A landscape ecology perspective generates different research questions focussed on different patterns, and at different scales, than conventional approaches in marine ecology. Such a perspective is more than a simple shift in emphasis because it requires a change in the way scientists conceptualise nature and the way they conduct their investigations (Wiens 1999). Landscape ecologists typically represent nature with distinct pattern-oriented constructs such as patches, patch mosaics, and spatial gradients in both 2-dimensional and multi-dimensional space and time (Wiens et al. 1993, McGarigal et al. 2009, Gustafson 2019). Landscape ecology concepts (e.g. corridors, connectivity, core area, edges, fragmentation) now permeate mainstream terrestrial ecology and conservation practice and feature prominently in global biodiversity policy (Turner 2005, McAlpine et al. 2010, Rees et al. 2018b, Dunn et al. 2019).
Seascape ecology draws heavily from conceptual and analytical frameworks developed in landscape ecology and focusses on understanding spatial pattern-process linkages in marine environments (Ray 1991, Robbins \& Bell 1994, Irlandi \& Crawford 1997, Boström et al. 2011, Pittman 2018b). Seascape ecology is an emerging science, with a growing cadre of ecologists worldwide increasingly applying the concepts and techniques of landscape ecology to the sea, generating new insights into the causes and ecological consequences of seascape patterns and processes (Pittman 2018a). Like landscapes, seascapes are considered heterogeneous spaces containing interacting components that typically exhibit scale dependence, non-linear dynamics, feedback loops, and emergent properties (Holling 1992, Levin 1992, Schneider 2001, Dajka et al. 2020). These systems properties present diagnostic attributes for understanding structure-function relationships and evaluating system status that are key to implementation of ecosystem-based management (EBM) (Levin \& Lubchenco 2008, Parrott \& Meyer 2012). Like landscape ecology, seascape ecology focusses on what we refer to here as the ' $4 \mathrm{Cs}^{\prime}$ ': context, configuration, connectivity, and the consideration of scale, an all-pervading concept. The term 'configuration' is used here as a broad class of spatial structure that encompasses the arrangement of patches, edges, and ecotones as represented in 2dimensional habitat maps and the 3-dimensional structure of the water column, sea surface, and seafloor topography (Fig. 1). A central tenet in landscape ecology is that the spatial configuration of landscapes is intertwined with ecological function such that when the former changes, the latter does as well (Turner 1989, Bell et al. 1991, Wiens et al. 1993)

As an ecological science, landscape ecology has evolved from multiple strands of pattern-oriented ecological and geographical thinking including island biogeography theory (MacArthur \& Wilson 1967), which stimulated pioneering research on patchiness in terrestrial and intertidal systems, on islands, and across the pelagic ocean (Simberloff \& Wilson 1969, Steele 1978, Bormann \& Likens 1979, Paine \& Levin 1981). Early investigation of patch configuration in shallow subtidal areas used natural experiments and artificial structures to explore the influence of patch size and isolation on faunal recruitment to determine whether marine reserves should be a single large patch or several small patches (e.g. seagrasses: McNeill \& Fairweather 1993; patch reefs: Schroeder 1987). At the time when landscape ecol- 


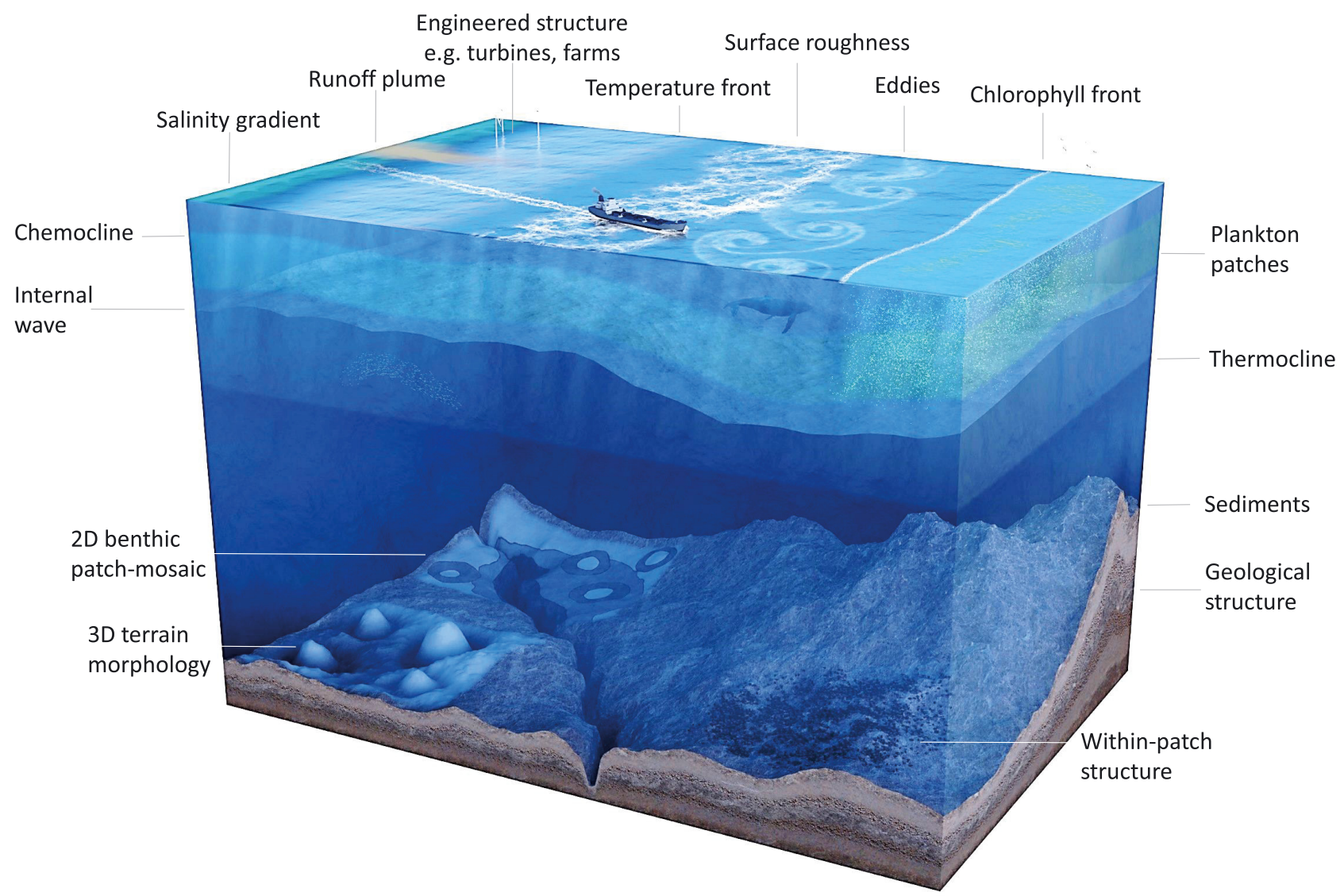

Fig. 1. Multi-dimensional seascape. A conceptualisation of pattern-forming structure in the ocean from the seafloor to the sea surface. Physical, chemical, and biogenic variables generate measurable, sometimes predictable, and often interconnected seascape structures such as surface topography, boundary layers, sediment plumes, plankton patches, and patch mosaics (adapted from Pittman 2018b)

ogy emerged as an ecological science, observations of fish movements were beginning to shed light on the influence of seascape configuration on functional connectivity across tropical patch mosaics (i.e. mangrove, seagrass, coral reefs) (Ogden \& Gladfelter 1983, Birkeland 1985, Parrish 1989). Over the past 30 yr since the term 'seascape ecology' (sensu Ray 1991) first entered the scientific literature, steady progress has been made in investigating the core principles of landscape ecology in the marine environment. Research has primarily focussed on benthic seascapes, sometimes referred to as benthoscapes (Zajac et al. 2000, Brown et al. 2011, Proudfoot et al. 2020), or marine landscapes, and most often applied to shallow coastal areas (Robbins \& Bell 1994, Pittman et al. 2004, Connolly \& Hindell 2006, Jackson et al. 2006, Boström et al. 2011, Bell \& Furman 2017). Renewed focus on 'ocean landscapes' (sensu Steele 1989), now referred to as pelagic seascapes (Alvarez-Berastegui et al. 2016, Hidalgo et al. 2016, Kavanaugh et al. 2016, Scales et al. 2018), and on seascape genetics (Selkoe et al. 2016) and seascape economics (Barbier 2018) is broadening the thematic scope of seascape ecology.

Data availability is also becoming less of a barrier to progress in seascape ecology as reliable marine geospatial data increase in quality, resolution, and diversity; but continued improvements to data access are crucial to facilitate greater progress (Huettmann 2011, Pendleton et al. 2019). At sea, international and multi-sectoral efforts for seafloor mapping are gradually filling gaps and updating the global bathymetry with high-resolution data (e.g. Seabed 2030 Project, Wölfl et al. 2019). Simultaneously, Earth observation monitoring systems capture and integrate huge volumes of diverse marine data to address pressing societal needs (Bax et al. 2019). The UN Decade of Ocean Science for Sustainable Development (20212030) will accelerate marine spatial data acquisition (Claudet et al. 2020) and further enable the development of seascape ecology as a sustainability science for the ocean. The effective application of an integrative multi-scale conceptual and operational framework is required for the interpretation of complex 
data into knowledge and insight needed to support transformative actions.

Although interest in seascape ecology is increasing globally (Pittman 2018b), there has been no coherent collaborative prioritisation of key research questions to help guide the future research agenda for applied seascape ecology. Through a consultative process, we asked seascape ecologists to formulate and then prioritise important applied research questions that would advance marine biodiversity conservation and sustainable development over the next decade. To bridge science and practice, we also invited practitioners of marine management, marine spatial planning, and conservation to prioritise important research questions (henceforth 'practitioners'). We used a 2-stage modified Delphi approach (Parsons et al. 2015, Yates et al. 2018) to make the process systematic and democratic (i.e. private voting). Delphi is an established structured information gathering and forecasting approach and has been used in a variety of research topics, including within ecology and biodiversity conservation, for consulting global expert opinion and judgements on the most important research questions and topics (Sutherland et al. 2013, Yates et al. 2018, Dey et al. 2020).

We first present the results of the most important research questions as prioritised by academic scientists (i.e. the authors of this work) and practitioners. These questions are grouped under 9 interconnected research themes. Next, we examine agreement in the research priorities perceived by academic scientists and practitioners to help determine where seascape ecology may have the greatest impact as a solution-focussed science. For each theme, we highlight key research challenges followed by discussion of the potential for seascape ecology to offer science that helps address the challenges of each theme. We suggest that these results may serve as a roadmap for applying seascape ecology for the UN Decade of Ocean Science for Sustainable Development (2021-2030). The results and discussion serve to inform an applied research agenda for seascape ecology and to highlight the broad scope of this emerging interdisciplinary science.

\section{MATERIALS AND METHODS}

\subsection{Modified Delphi methodology}

The coordination team (S. Pittman, K. Yates, and P. Bouchet) adapted a 2-stage modified Delphi survey methodology (Yates et al. 2018) conducted in 3 steps to first (Stage 1) solicit research questions and then prioritise research questions (Stage 2) through a 2step selection process (Fig. 2).

The 3 key steps were as follows. Step 1: A maximum of 5 research questions were solicited from academic scientists (including the coordinators) working at the forefront of seascape ecology along with a brief written rationale. Step 2: Academic scientists and practitioners selected all important questions from a curated list of the original questions grouped under 9 themes. Step 3: Academic scientists and practitioners selected their 10 most important questions from those they selected in Step 2.

Participants were asked to address the following when proposing research questions (see invitational letters in Text S1 in the Supplement at www.int-res. com/articles/suppl/m663p001_supp.pdf):

(1) Questions must be of broad geographical relevance, but can be focussed on any scale, with the condition that the question relates to measurable spatial patterns, patterning processes, or patternprocess relationships.

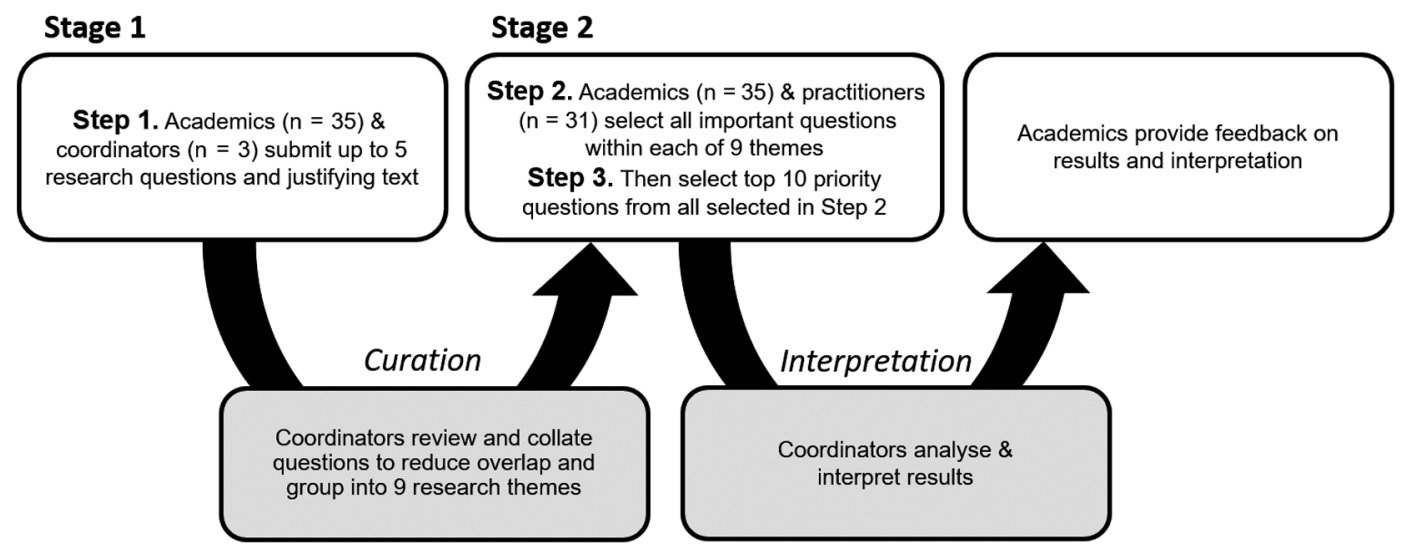

Fig. 2. Modified Delphi approach used for prioritising applied seascape ecology research questions. Both academic scientists and marine management/conservation practitioners were included in the consultative process 
(2) Questions must address a knowledge gap that will advance the practice of marine management, conservation, and marine spatial planning if adequately addressed within a decade.

\subsubsection{Selection of participants}

Academic scientists. We identified and invited 50 academic scientists based on their research interests in the application of landscape ecology concepts and tools to the marine environment, as evidenced through publications. Invitees included some of the coordinators' previous research collaborators. We also encouraged invitees to suggest suitable colleagues (i.e. referral sampling). Specialised ecological knowledge among the academics included fish and fisheries, seabirds, biological oceanography, ecoinformatics, remote sensing and habitat mapping, coral reef ecosystems, and saltmarsh and seagrass ecology, with research being conducted across a wide range of focal scales and geographical locations in temperate and tropical ecoregions.

Practitioners. We identified and invited 105 practitioners who were primarily senior staff at intergovernmental, governmental (national and local), or non-governmental organisations, and specialist marine management consultants. The key objective was to invite practitioners working in agencies that were likely to have a use for the knowledge emerging from seascape ecology. In the event of major gaps not addressed by the academics' research questions, coordinators invited practitioners to submit additional questions of their own. No additional questions were received.

The designation of respondents to a respondent group (i.e. academic scientist or practitioner) was based on the institution of employment at the time of completing the survey. Practitioner respondents were offered anonymity.

\subsubsection{Prioritisation survey}

The survey was designed using a professional online platform (Qualtrics ${ }^{\mathrm{TM}}$, Snow \& Mann 2013) to frame the task, assess the level of expertise, present the research questions, and quantify the survey results. This structured approach was designed to reduce known cognitive and methodological bias (Hallowell \& Gambatese 2010) and minimise the time required for participation. To reduce bias, the online questionnaire was delivered with each theme, and all questions within them, presented in random order.
Randomisation of the question order is an effective method for eliminating primacy and contrast biases. The contributor of each question remained anonymous to all participants other than the coordinators. Respondents were asked to self-assess their familiarity with seascape ecology on a discrete scale ranging from 1 (no knowledge) to 5 (expert), in half-point increments. The survey then proceeded in 2 steps of online voting. First (Step 2), respondents selected as many important questions from the curated list as they felt relevant to the task. Following this, respondents were presented with their selected questions and asked to identify from the shortlist the 10 most important questions. The final set of top-priority questions was identified based on the total number of votes each question received across all respondents.

\subsection{Data analysis}

To quantify and rank priority research questions, we calculated the proportion of all respondents in each of the 2 groups (academics and practitioners) that selected each question at Step 2 and Step 3. For the results of Step 3, only the proportion of votes received for each question selected was used to group questions into 3 priority classes using upper, middle, and lower terciles, whereby highest priorities are questions with the upper tercile percentage scores (i.e. the upper third of the data values). To avoid potential bias, the respondents were not aware of the coordinators' intention to classify the responses into 3 priority classes and had no knowledge of the intention to compare academic scientist priorities with practitioner priorities. Zeros were noted where a question was not selected. Cross-comparison of priority classes was conducted using a confusion matrix to evaluate the agreement between academics and practitioners. An unpaired Mann-Whitney test was used to determine if self-assessed familiarity with seascape ecology was significantly different between the 2 respondent groups.

\section{RESULTS AND DISCUSSION}

\subsection{Respondents' self-assessed knowledge of seascape ecology}

Of the 50 academic scientists contacted, 35 accepted the invitation to participate and submitted applied research questions and then fully completed the prioritisation questionnaire. Academics were affiliated with research institutions located in 9 countries 
(across 3 continents), with many having a global scope of work. Forty of 105 practitioners contacted engaged with the online questionnaire, resulting in 31 full completions and 9 incomplete questionnaires that could not be used in this analysis. Practitioners were based in 11 countries (across 4 continents), with many having a global scope of work. Most (91\%) academic scientist respondents had a moderate to high (score 3.5-5) level of self-assessed knowledge of seascape ecology, while $52 \%$ of practitioners had a moderate to high (score 3.5-5) knowledge of seascape ecology (Fig. 3). Six practitioners had low familiarity (score 1-2) with seascape ecology. The academic scientist population had a significantly higher $(4.2 \pm 0.7 \mathrm{SD})$ self-assessed knowledge of seascape ecology than the practitioner population $(3.2 \pm 1.2 \mathrm{SD})$ $(p<0.001)$. All completed questionnaires were included in the analyses. The lower familiarity with seascape ecology among practitioner respondents presents a key challenge to the transmission of results from seascape ecology into practice. Improving awareness of seascape ecology, however, can be addressed through co-design of demonstration projects, toolkits, training courses, meetings, and targeted communications (Norström et al. 2020).

\subsection{Curation of research questions}

A total of 139 research questions were submitted. Eleven questions that related to common challenges across the applied sciences (e.g. political governance, data management) were considered too broad to warrant inclusion. The remaining 128 research questions were assessed by the expert coordination team for redundancy. Repetition was removed by consolidating questions, with care to avoid any significant loss of key information from the original submissions, resulting in a curated set of 55 questions. Each question was assigned to 1 of 9 research themes based on the primary content of each question. Themes were defined as: seascape change; seascape connectivity; restoration and sustainability science; $\mathrm{EBM}_{\text {; }}$ seascape mapping, modelling, and sampling design; spatial and temporal scale; seascape goods and services; pelagic seascapes; and emerging technologies and metrics (Table 1). Some questions were relevant to multiple themes but were placed in a single theme for analysis. The largest grouping of questions occurred under the following 3 themes: (1) seascape change (11 questions); (2) seascape connectivity (10 questions); and (3) EBM (10 questions) (Table 1). The highest overlap in the content of the originally submitted questions occurred within the theme 'restoration and sustainability science', where 18 questions exhibiting considerable overlap were consolidated into 4 distinct questions. No additional research questions were received from practitioners.

\subsection{Relative importance among the 55 research questions}

From the 55 research questions presented to respondents in the questionnaire (Step 2, Fig. 2), the academic scientists selected an average of $32.4 \pm 9.4$ (SD) and practitioners selected an average of $34.1 \pm 9.2$ questions as being important to advance the practice of marine management, conservation, and spatial planning. The research themes 'spatial and temporal scale' and 'emerging technologies and metrics' were considered most important as priority research themes by both academic and practitioner respondents (Fig. 4).

\subsection{Highest-priority research questions}

The sum of the votes from academic scientists resulted in several of the 10 most important questions receiving equal ranking, thereby placing a total of 22 research questions within the top 10 priorities (Table 2). An additional 12 questions were selected

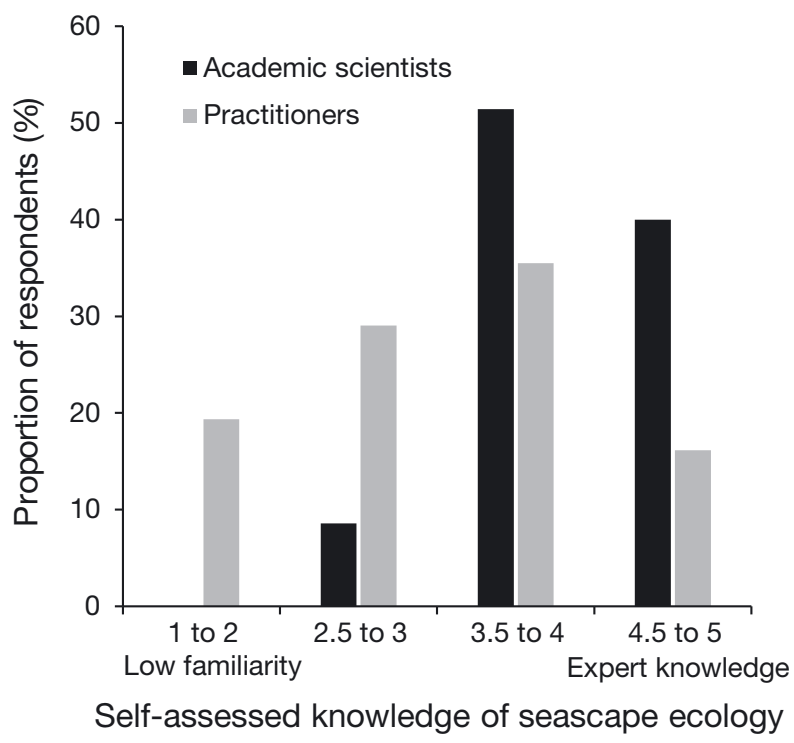

Fig. 3. Self-assessed knowledge of seascape ecology for all respondents from the academic $(n=35)$ and practitioner $(n=$ 31) sample groups. The discrete scale (0.5 increments) ranged from 1 for low familiarity of seascape ecology to 5 with expert knowledge. Intervals shown here are inclusive 
Table 1. Results of the curation process to reduce redundancy in content across all research questions grouped within 9 research themes

\begin{tabular}{|c|c|c|}
\hline $\begin{array}{l}\text { Research } \\
\text { theme }\end{array}$ & $\begin{array}{l}\text { Number of } \\
\text { questions } \\
\text { submitted }\end{array}$ & $\begin{array}{l}\text { Number of } \\
\text { questions } \\
\text { post-curation }\end{array}$ \\
\hline $\begin{array}{l}\text { 1. Seascape change } \\
\text { Dynamic spatial patterns and the ecological and social consequences of structural change }\end{array}$ & 29 & 11 \\
\hline $\begin{array}{l}\text { 2. Seascape connectivity } \\
\text { Movement of living and non-living material from one location to another and the ecological } \\
\text { and social consequences; human attachment and interactions with the ocean }\end{array}$ & 24 & 10 \\
\hline $\begin{array}{l}\text { 3. Restoration and sustainability science } \\
\text { Holistic spatial frameworks and systems science to inform human actions to address the } \\
\text { challenges of sustainability }\end{array}$ & 18 & 4 \\
\hline $\begin{array}{l}\text { 4. Ecosystem-based management } \\
\text { Ecological systems approach to management including spatial management strategies }\end{array}$ & 16 & 10 \\
\hline $\begin{array}{l}\text { 5. Seascape mapping, modelling, sampling } \\
\text { Spatially explicit pattern-oriented and multi-scale analytical methods and tools }\end{array}$ & 11 & 8 \\
\hline $\begin{array}{l}\text { 6. Spatial and temporal scale } \\
\text { Scale selection, scale effects, and multi-scale frameworks }\end{array}$ & 10 & 3 \\
\hline $\begin{array}{l}\text { 7. Seascape goods and services } \\
\text { Spatial patterns and ecological processes underpinning ecosystem services with a focus on } \\
\text { spatial context, configuration, and connectivity }\end{array}$ & 9 & 3 \\
\hline $\begin{array}{l}\text { 8. Pelagic seascapes } \\
\text { Dynamic spatial patterns and ecological processes in the open ocean and the linkages to } \\
\text { benthic ecology }\end{array}$ & 7 & 2 \\
\hline $\begin{array}{l}\text { 9. Emerging technologies and metrics } \\
\text { Spatial ecoinformatics, geospatial technologies, and advanced computing including } \\
\text { artificial intelligence }\end{array}$ & 4 & 4 \\
\hline Total & 128 & 55 \\
\hline
\end{tabular}

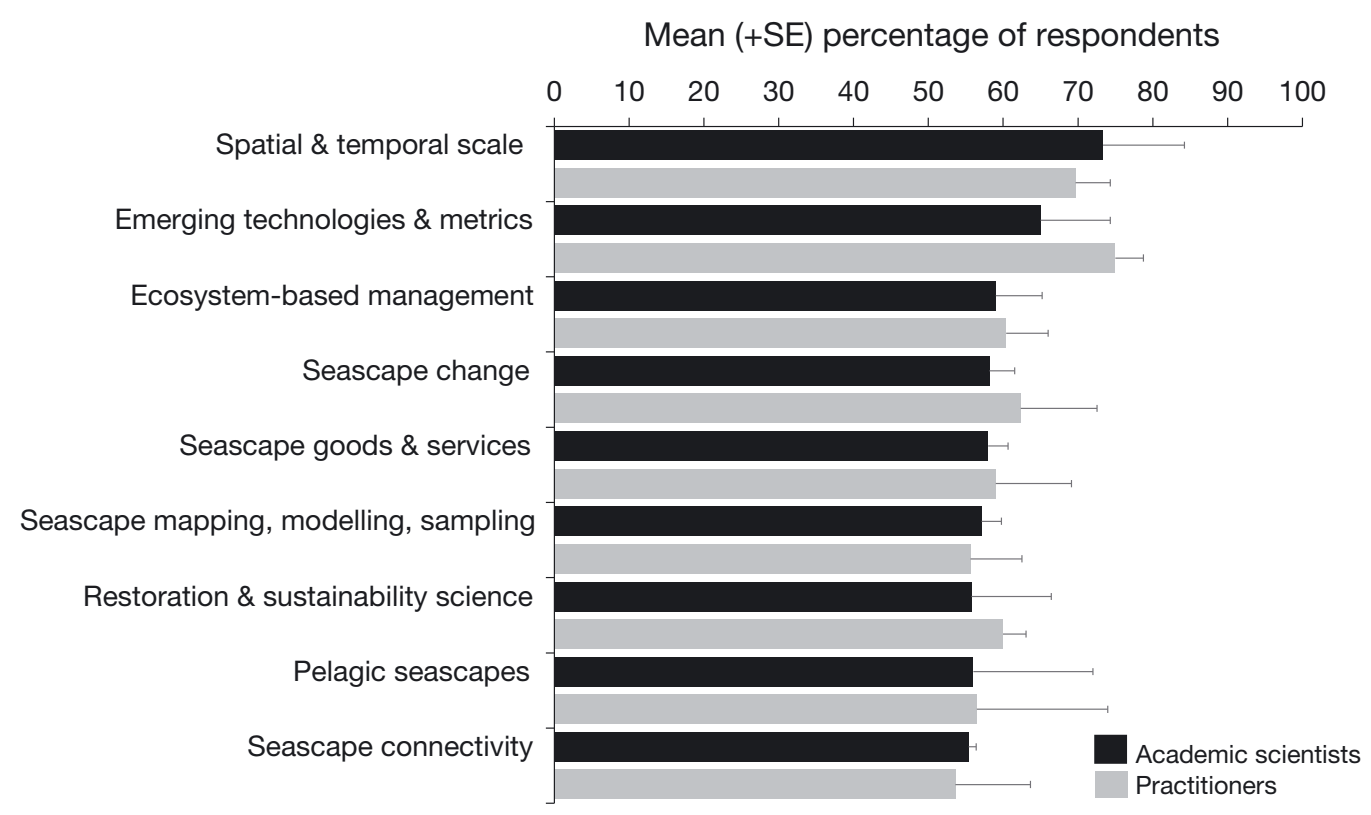

Fig. 4. Important research themes from Step 2 of the prioritisation process (see Fig. 2), presented as the proportion of academic scientists $(n=35)$ and practitioner $(n=31)$ respondents who selected research questions in each of the 9 research themes. Mean (+SE) calculated across all questions within a theme and plotted in descending order using the data from academic scientists 


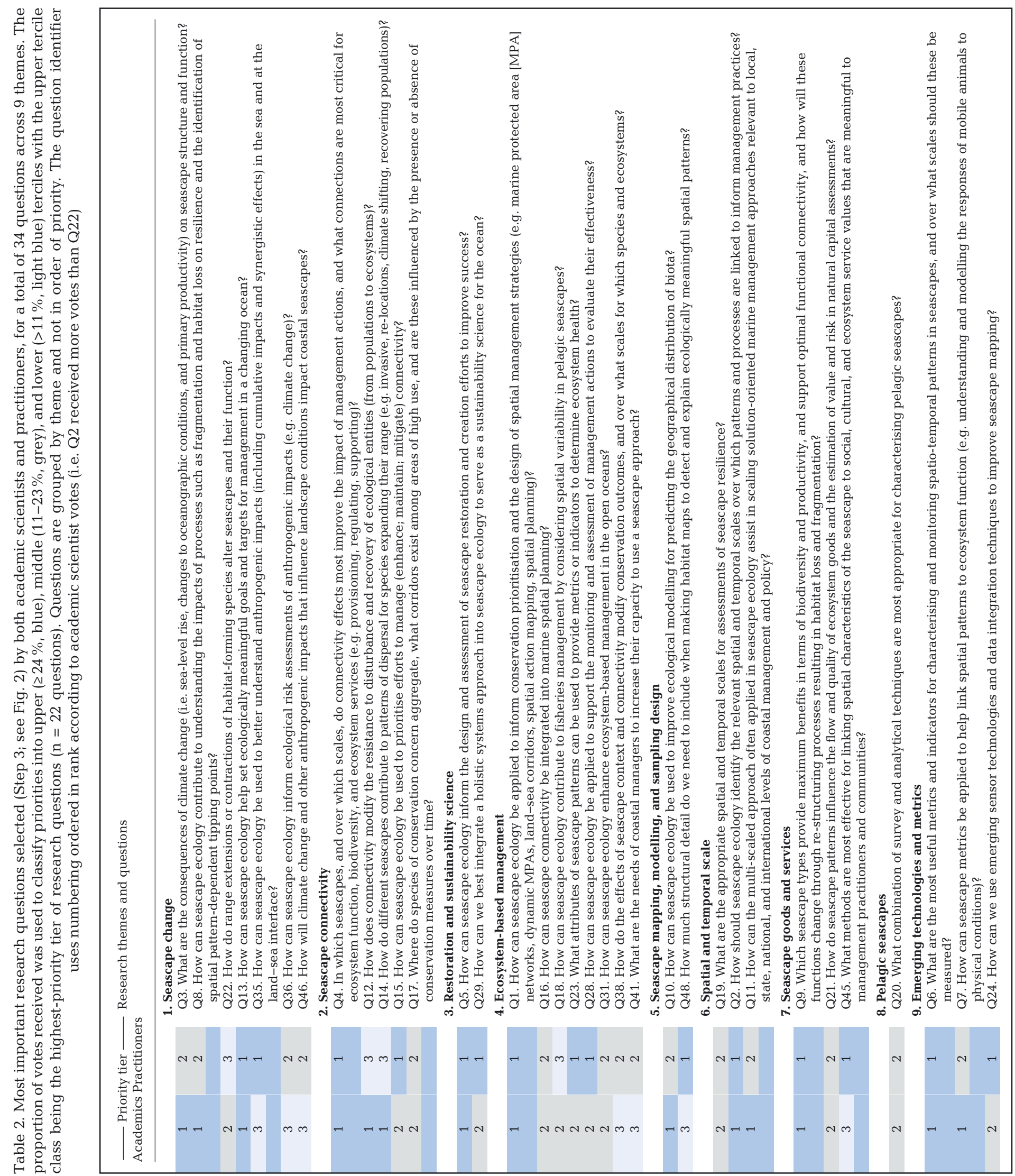


only by practitioners in Step 3, resulting in a total of 34 most important questions selected across both respondent groups. The grouping of all 55 questions into terciles based on Step 3 selections resulted in the following tercile categories: higher (upper tercile $\geq 24 \%$ ), medium $(11.7-23 \%)$, and lower $(\leq 11 \%)$ priorities (Table 2; see Table S2). Questions 1, 2, and 3 were selected as important by 91,94 , and $71 \%$ of the academic scientists, respectively, in Step 2 (Table S1) and as being amongst the 10 most important questions selected in Step 3 by more than $40 \%$ of academic scientists (Table 2; Table S2). Practitioners agreed that Q1 and Q2 were important in Step 2, receiving 84 and $77 \%$ of the votes, and a high priority in Step 3 (39 and 32\%) (Table S2). Q3 was important to $65 \%$ of practitioners in Step 2 and ranked tenth of 55 questions in Step 3. Combining the proportion of votes from Step 3 selections from both respondent groups ranked Q1, Q6, and Q5 as the 3 highest-priority research questions from Step 3.

\subsection{Agreement on the ten most important research questions}

Comparisons of the votes for the 10 most important research questions across all 55 questions (Table 2; Table S2) suggested that practitioners and academic scientists expressed highest agreement (59\%) on the lowest-priority questions, $50 \%$ agreement on the highest priorities, and lower agreement on medium $(32 \%)$ priority questions (Table 3$)$. The average difference in the proportion of votes received by each respondent group (across all 55 questions) was $9 \pm 7.5 \%$. Across all 3 priority tiers, 36 of the 55 questions were within a $\pm 10 \%$ band of agreement. Most notable disagreement on priorities was that 2 of the high-priority questions (Q12 and Q14) voted by academic scientists were classified as the lowest-priority tier by practitioners, and 3 of the lowest-priority questions for academic scientists (Q28, Q45, and Q48) were in the highest-priority tier for practitioners (Fig. 5). Overall, the highest disagreement occurred in the academic scientists' medium-priority tier, where 8 of 19 questions were in the lowest-priority tier for practitioners. Five of the high-priority academic scientist' questions (Q3, Q7, Q8, Q10, and Q11) were medium-tier priorities for practitioners. Two low-priority questions for academics received zero votes in the practitioners' top 10 research questions (Table $\mathrm{S} 2$ ).

Similar patterns of priorities between academics and practitioners have been reported elsewhere (Cvitanovic et al. 2013). For instance, the highest-ranking
(52\% of the vote) question (Q6) in the practitioners' top 10 was ranked fifth by academic scientists and focussed on identifying and applying useful metrics and indicators to characterise and monitor spatio-temporal seascape patterns. The greatest between-group difference, $28 \%$ higher for practitioners than academic scientists, was for Q28 on support for monitoring and assessment of the effectiveness of management actions. Question 22 on the impact of species range extensions and contractions on seascapes was a very low-priority question for practitioners but an upper medium-tier priority for academic scientists. Although many questions received same-tier agreement by both groups (26 of 55 questions) (Table 3), the diverging priorities represent an important difference in priority setting. This misalignment reflects the greater emphasis for practitioners on the need for science to support advances in monitoring and assessment, including metrics and indicators, and the need for a more holistic socioecological science that is better aligned with practice and policy (Dey et al. 2020). In the theme of EBM, 8 of the 10 questions were selected by practitioners in their 10 most important questions compared with 3 selected by academic scientists. In addition, practitioners prioritised addressing human impacts on the marine environment as a higher priority than research questions that focussed on marine organisms. For instance, Q35 on understanding human impacts in the sea and at the land-sea interface was placed in the highest-priority tier by practitioners and the lowest-priority tier by academic scientists.

Two of the research questions provided by academic scientists (Q50 and Q51) that focussed on metapopulations and teleconnections received zero selections

Table 3. Confusion matrix showing the proportion of all 55 research questions classified into each priority class (highest [blue], medium [grey], and lowest tercile [light blue]) based on the proportion of votes received by academic scientists and practitioners. The diagonal shaded boxes show the proportion of agreement between respondent groups for each priority class

\begin{tabular}{|lcccc|}
\hline \multirow{5}{*}{ Priority } & \multicolumn{4}{c|}{ Academic scientists } \\
& Highest & Medium & Lowest & Total \\
\hline Practitioners & & & & \\
Highest & 7 & 5 & 3 & 15 \\
& $(50 \%)$ & $(26 \%)$ & $(14 \%)$ & \\
Medium & 5 & 6 & 6 & 17 \\
Lowest & $(36 \%)$ & $(32 \%)$ & $(27 \%)$ & \\
& 2 & 8 & 13 & 23 \\
Total & $(14 \%)$ & $(42 \%)$ & $(59 \%)$ & \\
& 14 & 19 & 22 & 55 \\
\hline
\end{tabular}




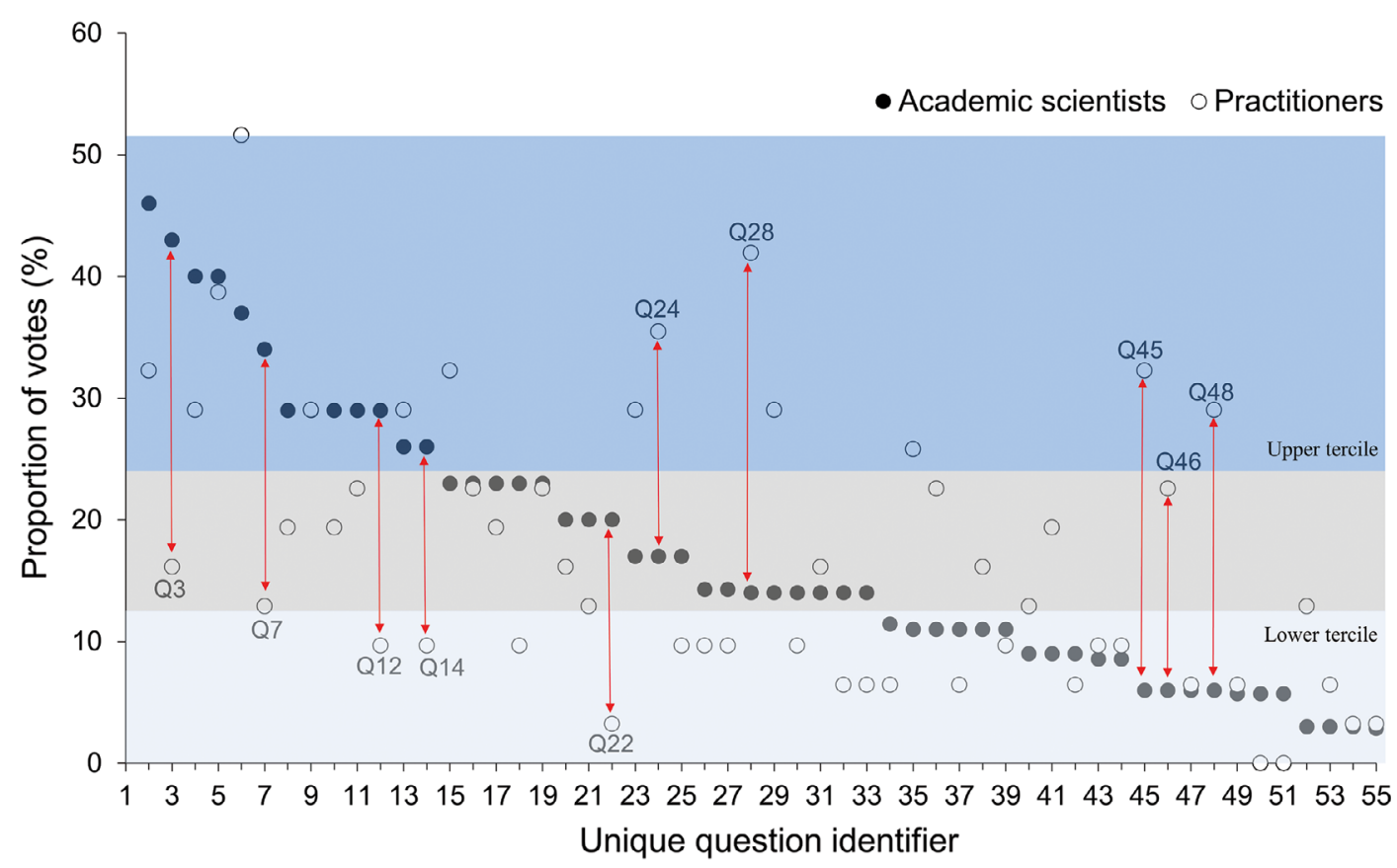

Fig. 5. Proportion of votes by question for the 10 most important research questions (Step 3 of prioritisation; see Fig. 2) cast by academic scientist and practitioner respondent groups. The 10 questions with the greatest disparity between respondent groups are numbered and identified using red arrows. Upper tercile questions (blue) represent the highest priority, and lower tercile questions (light blue) represent the lowest priority

in the practitioners' top 10 and very few $(6 \%)$ selections by academic scientists. Despite receiving increasing interest from landscape ecologists (Liu 2017, Raya Rey \& Huettmann 2020), research on distant teleconnections is often focussed on highly mobile species and pattern-process relationships across multi-decadal timescales and spatial scales far broader (i.e. ocean basin, spanning hemispheres) than is typical in seascape ecology. Although congruence between academic scientists and practitioners was mixed across the 3 priority tiers, the importance of seascape ecology research to practitioners was emphasised by agreement on 12 of the 22 top-ranked questions, including the agreement on 5 of the 6 highest-ranking questions.

Among the places of disagreement, question 45 ('What methods are most effective for linking spatial characteristics of the seascape to social, cultural, and ecosystem service values that are meaningful to management practitioners and communities?') was ranked in the highest-priority tier by practitioners and lowestpriority tier by academics. This apparent disconnect between science and practice reflects an expected disparity between seascape ecologists who primarily focus on marine organismal ecology and practitioners who are more likely to focus on complex socioeconomic, political, and cultural issues linked to marine management. To some extent, voting choices may be biased by individual experience, interests, pressing environmental policy, current trends in topics, perceived barriers to progress, and the phrasing and familiarity of questions that may infer either a more solution-focussed or more basic science-focussed problem (Drescher et al. 2013). Furthermore, we acknowledge that the design of surveys, including the way tasks are presented for expert judgement, will have an associated cognitive bias that is method dependent. Differences emerging from the 2 respondent groups may also be the result of the demonstrated lower awareness of seascape ecology in the practitioner group. However, the major differences, as expected, are more likely reflective of the greater importance to practitioners of reliable tools and information to help prioritisation, implementation, and effectiveness of actions. Although not discussed here, we acknowledge that many cultural drivers will have a bearing on the application of seascape ecology to practice, including global governance, political and economic systems, knowledge exchange, and data access.

\subsection{How seascape ecology can help address applied research challenges}

For each research theme, we list here only the single highest-ranked research question resulting from the votes from each respondent group. All others are 
provided in Table 2 (and Tables S1 \& S2). To contextualise all questions within each research theme, we provide a broad synthesis of key research challenges and a horizon scan exploring the potential for seascape ecology to address these challenges.

\subsubsection{Theme 1: Seascape change}

The highest-priority research question in the theme of seascape change was Q3, ranked third by academic scientists and tenth by practitioners. For practitioners, Q13 was the highest priority (ranked sixth) and ranked eighth by academic scientists.

Q3: What are the consequences of climate change (i.e. sea-level rise, changes to oceanographic conditions, and primary productivity) on seascape structure and function?

Q13: How can seascape ecology help set ecologically meaningful goals and targets for management in a changing ocean?

Research challenges. Despite recognition that spatial patterns can be used to investigate change and predict resilience (Levin 1992, Kelly et al. 2011, Kavanaugh et al. 2016), the spatially explicit patterns of seascape change are often overlooked, hindering our ability to anticipate and mitigate the adverse consequences of structural change. For instance, the composition and spatial configuration of coastal seascapes is being changed by accelerated climate change and other human impacts (e.g. loss, expansion and fragmentation of seagrass beds, kelp beds, saltmarshes, and mangroves) (Halpern et al. 2019). Across the global tropics, remote sensing data from air- and space-borne sensors have revealed the complex spatial and temporal patterns in the biological responses of corals to marine heat waves (Page et al. 2019). Such complex changes emerging at multiple scales justify the application of pattern-oriented scientific methods in attempts to understand and predict the consequences of changing seascape structure on ecological functions (Wu 2019, Bryan-Brown et al. 2020) and to identify spatial threshold effects (Yeager et al. 2016, Santos et al. 2018). Bridging science and practice for a better understanding of change will require innovative and integrative spatial frameworks with pattern-oriented indicators to inform spatial planning, restoration design, and ecosystembased climate adaptation strategies (Babí Almenar et al. 2018, Paulo et al. 2019).

Application. Seascape ecology recognises that environmental change plays out as a pattern-forming ecological process operating across multiple scales (Levin 1992). The application of concepts, spatial models, and spatial pattern metrics from landscape ecology has been transformative in understanding coastal ecosystem dynamics at spatial scales that are operationally relevant to management decision making (Browder et al. 1985, Costanza et al. 1990, Hovel \& Regan 2008, Santos et al. 2018). Advances in computation are continually improving efforts to incorporate more complex patterns and processes into modelling at finer resolutions and across broader spatial and temporal scales. Integrating behavioural responses to spatial patterns into spatial models, such as in individualbased models (Stillman et al. 2015, Hovel \& Regan 2018), and increased performance of multi-scale predictive mapping (Pittman \& Brown 2011, Hattab et al. 2014, McGarigal et al. 2016) will help reduce uncertainty in our efforts to explain and forecast the ecological consequences of seascape shifts under a changing climate. For example, linking the patterns of structural change in habitat to ecological processes such as predator-prey dynamics and the implications for food web structure can inform management decisions (Gilby et al. 2020b). For the open ocean, the merging of hierarchy theory and patch dynamics with oceanographic and ecological paradigms provides an ecological framework with implications for advancing dynamic ocean management for sustainable fisheries and biodiversity conservation (Hidalgo et al. 2016, Kavanaugh et al. 2016), which will be a valuable management approach as species' ranges continue to shift. Predicting marine species' geographical range shifts in response to ocean warming will benefit from greater integration of interacting spatial factors (e.g. benthic seascape configuration and connectivity) that will, for many species, also affect habitat suitability, organism movements, and capacity to adapt (McHenry et al. 2019, Cattano et al. 2020, Lauchlan \& Nagelkerken 2020, Morley et al. 2020). Such complex challenges will require advances in data integration and a seascape ecology framework capable of adopting systems science concepts and techniques and the capacity to integrate information from movement ecology, oceanography, genomics, metapopulation biology, and socio-economics (Fowler et al. 2013, Liu et al. 2015, Lowerre-Barbieri et al. 2019). Information on the interlinked spatial components of seascapes will help to broaden the scale at which structural and functional ecosystem integrity is defined, with potential for creation of indices of seascape condition that inform management goals and actions in a changing climate. 


\subsubsection{Theme 2: Seascape connectivity}

The highest-priority research question in the theme of seascape connectivity was Q4, ranked fourth by academic scientists and sixth by practitioners. For practitioners, Q15 was the highest priority (ranked fifth) and ranked ninth by academic scientists.

Q4: In which seascapes, and over which scales, do connectivity effects most improve the impact of management actions, and what connections are most critical for ecosystem function, biodiversity, and ecosystem services (provisioning, regulating, supporting)?

Q15: How can seascape ecology be used to prioritise efforts to manage (enhance, maintain, mitigate) connectivity?

Research challenges. In many locations, it remains unclear how human activities have modified the material flux between landscapes and seascapes and disrupted life cycle connectivity and the flow of ecosystem services from coastal ecosystems, as well as how best to restore, create, and protect ecological connectivity (Olds et al. 2016, Carr et al. 2017, Balbar \& Metaxas 2019). A key research challenge is to determine the ecological functions that are modulated by connectivity and identify the spatial and temporal scale(s) over which these functions enhance ecosystem services and conservation outcomes (Olds et al. 2016, Weeks 2017, Theuerkauf et al. 2019). This also extends to often complex interactions between distant places (telecoupling) that can lead to unexpected outcomes with important implications for sustainability (Liu et al. 2013, Raya Rey \& Huettmann 2020). Connectivity is also an important process in the deep sea, where longterm monitoring has revealed mass fish migrations synchronised with seasonal cycles of primary productivity, connecting surface waters with the deep (Milligan et al. 2020).

Globally, the maintenance and restoration of riversea and land-sea functional connectivity for the many species that require unimpeded structural habitat connectivity to close their life cycles is a pressing and complex challenge (Beger et al. 2010). The socioeconomic consequences of ecological connectivity are receiving growing interest (Rees et al. 2018b, Popova et al. 2019), yet we still know relatively little of the linkages between ecological connectivity and provisioning of ecosystem services (Barbier 2018). Efforts are underway globally to synthesise and integrate information on ecological connectivity for effective spatial planning and global biodiversity conservation with potential to advance the emerging ecological concepts such as blue corridors, ecological networks, and pelagic MPAs (Pittman et al. 2014, Schill et al. 2015, Dunn et al. 2019).

Application. Connectivity is a core concept in seascape ecology. Seascape connectivity describes the degree to which a seascape facilitates or hinders the movement of organisms, or the flow of genetic material, nutrients, and other matter (Grober-Dunsmore et al. 2009). Seascape ecology can help advance the integration of seascape connectivity into decision support tools and best practice principles that inform actions that maintain connectivity and rehabilitate dysfunctional connectivity (Watson et al. 2017, Waltham et al. 2019). Furthermore, better integration of seascape structure and function into coupled biophysical connectivity modelling will improve tools to predict pathways and consequences of invasive species, pathogens (Kough et al. 2015), and the spread of regime shifts (Hughes et al. 2013) to inform mitigation and adaptation strategies.

Specific connectivity metrics and software for modelling actual, structural, and potential connectivity have been created and applied to terrestrial landscapes, freshwater ecosystems (e.g. riverscapes), and seascapes (Calabrese \& Fagan 2004, Virtanen et al. 2020). Indirect estimations, or potential connectivity, can be measured and modelled using probabilistic or predictive spatial models of movement or habitat distributions (Lowe \& Allendorf 2010, Treml et al. 2015, Puckett \& Eggleston 2016). Graph-theoretical methods, as used in landscape ecology, provide an effective tool to visualise complex patterns of spatial connectivity at scales that are operationally relevant to management with demonstrated contributions to conservation planning (Treml \& Halpin 2012, Saunders et al. 2016). Neutral seascape models allow us to test and explore through spatial simulations the influence of simplified seascape configuration, hydrodynamics, and scale on organism space-use strategies (Caldwell \& Gergel 2013). Dynamic models of potential connectivity, especially propagule dispersal, have received considerable attention in marine systems regarding sources and sinks, marine metapopulations (Kool et al. 2013, Treml et al. 2015, Puckett \& Eggleston 2016), and the design and performance of MPA networks (Carr et al. 2017, Jonsson et al. 2020).

A wide variety of ecosystem services depend on the movement of organisms and materials across seascapes and between land and sea. For example, the fisheries ecosystem service value can be influenced by seascape connectivity of coastal marine ecosystems, with well-documented examples including interconnected nursery habitats referred to as 'seascape nurseries' (Nagelkerken et al. 2015, Perry et al. 
2018, Berkström et al. 2020). Identification of areas of critical habitat and ecological connectivity for sustaining biodiversity and ecosystem services is increasingly required for spatial conservation planning (Mumby 2006, Weeks 2017, Yates et al. 2019, Proudfoot et al. 2020).

Spatial pattern metrics quantifying benthic seascape connectivity can help design protected areas that maximise structural connectivity (Engelhard et al. 2017, Weeks 2017, Proudfoot et al. 2020). Improved functionality in spatial planning software enables data on actual and potential ecological connectivity to play a role in the design of conservation measures such as protected area networks (Virtanen et al. 2020). Increased sophistication in analytical techniques for multi-dimensional and cross-scale analyses of fluid processes will advance our capability to understand and better manage vertical connectivity (e.g. nutrient exchange) coupling benthic and pelagic components (Griffiths et al. 2017). Seascape ecology must also begin to include the multi-scale spatial patterns and processes of the often overlooked marine microbial communities. For example, marine microbes play a crucial role in the vertical transport of material and nutrient cycling, yet we know little of the interconnectedness between microscopic and macroscopic patterns and processes.

\subsubsection{Theme 3: EBM}

The highest-priority research question in the theme of EBM was Q1, ranked first by academic scientists and third by practitioners. For practitioners, Q28 was the highest priority (ranked second) and ranked $12^{\text {th }}$ by academic scientists.

Q1: How can seascape ecology be applied to inform conservation prioritisation and the design of spatial management strategies (e.g. MPA networks, dynamic MPAs, land-sea corridors, spatial action mapping, spatial planning)?

Q28: How can seascape ecology be applied to support the monitoring and assessment of management actions to evaluate their effectiveness?

Research challenges. Calls for more holistic and inclusive approaches to marine management and conservation that consider local ecological knowledge and social justice (Bennett 2018) present important challenges for scientific research and for the evolution of a sustainability science for the ocean. EBM is an integrated approach to place-based management that considers the entire ecosystem, including humans, with the goal to 'maintain an ecosystem in a healthy, productive and resilient condition' (McLeod et al. 2005, p. 1). The application of ecological principles, including those from landscape ecology, have been linked to the implementation of EBM, such as the design of MPAs, coherent MPA networks, and broader marine spatial planning (Roberts et al. 2003, Crowder \& Norse 2008, Foley et al. 2010). For example, achieving qualitative elements of the Aichi Biodiversity Target 11 by 2020 required spatially explicit information on the $4 \mathrm{Cs}$ of seascape ecology to design 'ecologically representative and well-connected systems of protected areas... integrated into the wider landscape and seascape' (Convention on Biological Diversity; www.cbd.int/sp/targets/rationale/target-11/). However, those criteria are rarely achieved or assessed in practice (Rees et al. 2018a,b, Meehan et al. 2020).

Application. With a focus on multi-scale system complexity, we suggest that seascape ecology provides an appropriate framework to enhance the contribution of ecological science to both goal setting and provisioning of evidence when addressing biodiversity conservation and sustainable development goals. Concepts familiar to landscape and seascape ecologists such as ecological connectivity, corridors, ecological networks, scale-effects, and habitat fragmentation permeate marine conservation and spatial planning through EBM (Crowder \& Norse 2008). Similarly, core concepts from landscape ecology increasingly bridge the science-policy gap, playing a central role in national and global policy for biodiversity conservation, restoration, and sustainable development (Choi et al. 2008, Opdam et al. 2018, Rees et al. 2018a, Balbar \& Metaxas 2019).

From an operational perspective, adaptive monitoring will require spatial pattern metrics that reflect function, including novel ocean-specific metrics capable of serving as condition indicators (e.g. frontal densities, patchiness, and gradients in kinetic energy) (Miller \& Christodoulou 2014, Alvarez-Berastegui et al. 2016). Spatial tools for systematic conservation planning that assist in prioritising places for conservation action have been ecologically refined with principles from landscape ecology (Beger et al. 2010, Oleson et al. 2018). Development of pattern-oriented adaptations of incisive systems approaches, such as causal chain analysis (Qiu et al. 2018) and the DriversPressures-State Change-Impact-Response framework (Matta \& Serra 2016), could facilitate the integration of seascape patterns into holistic ecosystem assessments (Dreujou et al. 2020). Although rarely identified in seascapes, spatial leverage points where a small shift in spatial configuration can produce large and sometimes abrupt changes, could provide an effective 
tool for prioritising actions for mitigation of human impacts and predicting spatial resilience. Progress in addressing all of the priority research questions across all 9 cross-cutting themes will support the implementation of EBM.

\subsubsection{Theme 4: Restoration and sustainability science}

The highest-priority research question in the theme of restoration and sustainable development was Q5, ranked fourth by academic scientists and third by practitioners. Both groups voted with a high agreement (40 and $39 \%$, respectively).

Q5: How can seascape ecology inform the design and assessment of seascape restoration and creation efforts to improve success?

Research challenges. Our understanding of ecological complexity has profound implications for the way that we perceive the world, our place in it, and how we design actions to restore ecosystems and achieve sustainable development (Levin 1992, Wu 2013). To help society address the many challenges of managing for sustainable seascapes, ecologists will need to advance integrative and transdisciplinary approaches to study socioecological systems (Opdam et al. 2018, Pittman et al. 2018, Alexander et al. 2019). The need for ecological science to support transition to an alternative economic development model (e.g. steadystate, degrowth) and the challenge to realise a 'sustainable blue economy' will rise in prominence with the rapid growth and diversification of ocean and coastal uses (Huettmann \& Czech 2006, Jouffray et al. 2020). Linking spatial characteristics of the seascape to functions, values, and metrics that are meaningful to decision-makers will facilitate communication and knowledge exchange among academic scientists, management practitioners, industry, and community groups.

In 2019, the UN General Assembly declared 2021-2030 the 'UN Decade on Ecosystem Restoration', calling for accelerated global action to restore degraded ecosystems (Duarte et al. 2020). Restoration of coastal seascapes, however, presents a complex and often financially costly intervention with a highly variable short-term performance for some habitat types and locations (Bayraktarov et al. 2016, van Katwijk et al. 2016), and measurable success for others (e.g. seagrass beds in the USA: Rezek et al. 2019; kelp forests in Australia: Layton et al. 2020). A global review of 89 coastal marine restoration projects revealed that only $13 \%$ considered landscape context in site selection, yet of those that did, $60 \%$ supported larger and more diverse animal populations than control areas (Gilby et al. 2018b). Spatially explicit and ecology informed transdisciplinary approaches stand to benefit habitat and seascape restoration through optimal site selection, enhanced ecological design, improved prediction of post-restoration ecological trajectories, and addressing the challenges of scaling up restoration efforts (Bell et al. 1997, Gilby et al. 2018b, Waltham et al. 2020).

Application. Seascape ecology has great potential to support restorative and sustainability science through a place-based, multi-scale, whole-system understanding of the dynamic spatial relationships among seascape structure, ecosystem services, and human wellbeing (Cumming 2011, Wu 2013, Opdam et al. 2018). We suggest that a scientific consideration of how the $4 \mathrm{Cs}$ can influence the success of coastal restoration strategies and help anticipate consequences for neighbouring areas will advance seascape restoration (Bell et al. 1997, Gilby et al. 2018a, 2020a). Although evidence for the importance of the $4 \mathrm{Cs}$ on the ecological performance of management actions is increasing, in some settings these attributes are still not considered sufficiently at the design stage in restoration projects (Simenstad et al. 2006, Gilby et al. 2018b, Lester et al. 2020). Most coastal restoration efforts focus on single habitat types (e.g. seagrass, saltmarsh, oyster reef, mangrove), with site selection typically omitting consideration of the spatial configuration of restored sites and the patterns of connectivity (Lester et al. 2020). A shift in perspective from a single patch type to a patch mosaic, or seascape type, promotes a more comprehensive consideration of species connectivity, seascape configuration, community-level processes, external threats, feedback loops, ecosystem service flows, and connectivity with the wider landscape and seascape. Where restoration goals seek to optimise co-benefits from restored seascapes (e.g. climate mitigation from blue carbon, coastal protection, biodiversity, and food security), a spatially explicit focus on the $4 \mathrm{Cs}$ should inform strategies and expectations (Moberg \& Rönnbäck 2003, Simenstad et al. 2006, Barbier 2017 , Gilby et al. 2020a). Seascape ecology has the potential to provide spatial design principles for seascape restoration based on the $4 \mathrm{Cs}$.

Active restoration projects present excellent opportunities for field experiments on pattern-process relationships (Ellison et al. 2020); however, it is spatial modelling in landscape ecology that has been more often used as a powerful and flexible tool to evaluate site suitability, explore different spatial 
design scenarios, and analyse trade-offs to guide actions (Sleeman et al. 2005, Brudvig et al. 2017, Lester et al. 2020). Although rarely examined, knowledge of seascape configuration could provide information to calculate habitat availability and carrying capacity for recovering populations in response to protection or habitat restoration, as well as to identify spatial limitations and bottlenecks to recovery. In addition to informing innovative seascape restoration science, seascape ecologists will be effective knowledge brokers in the evaluation of learning from broad-scale terrestrial landscape restoration studies, with potential benefit to scaling up the restoration of coastal seascapes.

\subsubsection{Theme 5: Seascape mapping, modelling, and} sampling design

The highest-priority research question in the theme of seascape mapping, modelling, and sampling design was Q10, ranked seventh by academic scientists and ninth by practitioners. For practitioners, Q48 was the highest priority (ranked sixth) and ranked $15^{\text {th }}$ by academic scientists, highlighting a substantial $(23 \%)$ divergence of agreement between the 2 groups.

Q10: How can seascape ecology be used to improve ecological modelling for predicting the geographical distribution of biota?

Q48: How much structural detail do we need to include when making habitat maps to detect and explain ecologically meaningful spatial patterns?

Research challenges. Determining which patterns to measure and how to measure them remains a pervasive challenge in marine ecology and management (Levin 1992, Capotondi et al. 2019). A significant outstanding challenge lies in developing mapping techniques that incorporate dynamic processes, including sub-surface patterns (Brodie et al. 2018), to facilitate the linking of structure and function. Geospatial products such as benthic habitat maps and maps of pelagic structure (e.g. ocean fronts) are important spatial data that enable ecological analyses and often form the foundational data layers for the development of marine spatial planning and a wide range of area-based sampling, monitoring, and conservation actions (Cogan et al. 2009, Brown et al. 2011, Miller \& Christodoulou 2014). Working with maps in ecology presents a wide variety of methodological challenges associated with thematic and spatial resolution, as well as temporal dynamics (Lechner \& Rhodes 2016). Mismatches between ecological, observational, and analytical scales can be problematic because they can bias specieshabitat relationships and constrain ecological questions (Brown et al. 2011, Lecours et al. 2015). Increasingly, however, targeted research-led mapping has focussed on capturing ecological patterns that specifically consider species, communities, and biodiversity elements of the seabed and water column (Colbo et al. 2014, Costa et al. 2014, Lacharité \& Brown 2019). Most habitat maps used in ecology are static products representing snapshots of structure and requiring repeat mapping over time to capture meaningful ecological dynamics. This may only be needed infrequently for relatively stable structures (e.g. seafloor geology) or when tracking long-term change (Santos et al. 2016). However, pelagic seascapes require a dynamic geographic framework with near-real-time mapping of fluid patterns and processes to advance dynamic ocean management (Maxwell et al. 2020). Predictive models suggest that dynamic spatial management can improve risk management in fisheries and meet conservation objectives in the face of changing ocean conditions (Hazen et al. 2018, Welch et al. 2019). Maps and ecological models of seascape patchiness, spatial gradients, and scale effects also have an important role to play in sampling design, particularly when assessing human impacts and monitoring the effectiveness of management actions (Hewitt et al. 2007, Sandel \& Smith 2009). The potential for bias from inadequate consideration of variability in the $4 \mathrm{Cs}$ has received little attention in both landscape and seascape ecology, yet has considerable implications for data acquisition, analyses, and interpretation.

Application. Seascape mapping enables the acquisition of baseline information, the evaluation of EBM strategies, and explorations of research questions relevant to seascape ecology (Brown et al. 2011, Wedding et al. 2011, Lecours et al. 2015). The primary use of seascape maps has been to quantify and compare seascape patterns and pattern-forming processes at a range of spatial and temporal scales and to explore linkages between seascape patterns and animal distributions (Boström et al. 2011, Staveley et al. 2017, Lacharité \& Brown 2019). Novel integration of stable isotope data with remote sensing to map species' energetic resources across seascapes is one example of integrative seascape ecology thinking that is advancing our pattern-process understanding (James et al. preprint https://doi.org/10.1101/2020.08. 03.234781). Seascape ecologists can be both makers and end-users of maps, demonstrating technical skills, knowledge of ecologically meaningful scales, and understanding of the limitations and uncertain- 
ties at all stages of data collection, processing, analysis, and interpretation (Wedding et al. 2011). Emphasis is placed on the choice of conceptual model for representing seascape structure (patch matrix, patch mosaic, gradient models; McGarigal et al. 2009), understanding and quantifying the effects of thematic and spatial map resolution, map classification, the scale of analyses, and any bias caused by the propagation of spatial errors through the analytical process (Kendall et al. 2011, Wedding et al. 2011, Lecours et al. 2015, Lecours 2017). Adopting such novel, multi-scale techniques from landscape ecology has advanced spatial predictive modelling, with examples from shallow tropical waters (Pittman et al. 2007, Purkis et al. 2008, Wedding et al. 2008, Stamoulis et al. 2018), temperate waters (Pittman \& Costa 2010), Arctic waters (Huettmann et al. 2011, Misiuk et al. 2018), deep-sea environments (Ross \& Howell 2013), and the global ocean (Wei et al. 2010). Application of machine-learning algorithms that allow interactions between predictor variables across multiple spatial scales have enabled seascape heterogeneity to be better considered, leading to new hypotheses on ecological responses and boosted model performance (Huettmann \& Diamond 2006, Pittman \& Brown 2011, Humphries et al. 2018, Lacharité \& Brown 2019). Future technological advances will likely see these predictive mapping techniques applied to 3- and 4-dimensional seascapes through multidimensional data cubes, with potential to play a valuable role in ecology and marine spatial planning, such as modelling water column structure or organism movement pathways (Tracey et al. 2014, Papastamatiou et al. 2018, Demšar \& Long 2019, Melo-Merino et al. 2020) and predicting 4-dimensional shifts in species distributions due to global warming.

A growing body of evidence also suggests that the $4 \mathrm{Cs}$ influence seascape function. These variables must therefore be considered in sampling designs, especially when selecting impact and control sites (e.g. when comparing performance between unprotected and protected areas; Huntington et al. 2010, Olds et al. 2012, Rees et al. 2018). Sub-optimal sampling designs could result from the lack of consideration of the $4 \mathrm{Cs}$, with potential to bias results in comparative studies leading to erroneous conclusions on the effectiveness of management actions. Where benthic maps are available, seascape ecology can help recognise context-dependency (Bradley et al. 2020) and can facilitate re-analyses of historical data with inclusion of seascape patterns and shift focus to habitat mosaics, or 'seascape types' (sensu Pittman et al. 2007) instead of single habitat types (Pasher et al. 2013, Bradley et al. 2020). Although few examples exist, spatially explicit simulation modelling can be used to optimise sampling designs that account for seascape patterns, processes, and scale (Albert et al. 2010, Zurell et al. 2010, Hovel \& Regan 2018).

\subsubsection{Theme 6: Spatial and temporal scale}

The highest-priority research question in the theme of spatial and temporal scale was Q2, ranked second by academic scientists and fifth by practitioners. Both groups voted this question into the highestpriority tier (46 and $32 \%$, respectively).

Q2: How should seascape ecology identify the relevant spatial and temporal scales over which patterns and processes are linked to inform management practices?

Research challenges. Scale is fundamental to all of ecology and presents a unifying challenge for academic scientists and practitioners that pervades many, if not all, applications of ecological science to management practice and policy (Levin 1992, Schneider 2001, Cumming et al. 2006, Guerrero et al. 2013). Inadequate accounting of scale and inappropriate scale selection can result in inflated uncertainty, incomplete interpretation of cause-effect relationships, and, at worse, can mislead decision making (Meentemeyer 1989, Cumming et al. 2006). The scale of observation can have profound consequences for the interpretation of results, with different patterns emerging at different scales of investigation (Huettmann \& Diamond 2006, Schneider 2009, Pittman \& Brown 2011, Fernandez et al. 2017). For instance, species-environment associations can change from strongly positive to strongly negative with a change in the scale of analysis (Wiens et al. 1987, Huettmann \& Diamond 2006). Cross-scale analyses of predator-prey interactions in pelagic seascapes suggest that physiological and ecological parameters vary according to spatial and temporal scales and can be closely coupled (Steele 1989), yet cross-scale interactions can often increase uncertainty in EBM (Glaser \& Glaeser 2014). The appropriate selection of temporal scales also presents a research challenge that has been made more urgent by accelerated seascape change where mismatches in the temporal scale of dynamic phenomena (e.g. non-stationarity, evolution, asynchronous behaviour, shifts in scheduling) can undermine the identification of causative variables and impede the application of science to practice (Wolkovich et al. 2014). 
Although rarely executed sufficiently in conventional marine ecology, the explicit consideration of scale is necessary at every step of the research process, from the framing of hypotheses to the collection of data, the design of field experiments and from analyses to interpretation and application (Schneider 2009, Wedding et al. 2011, Lecours et al. 2015).

Application. A preoccupation with scale, especially spatial scale, is a defining trait of landscape and seascape ecology and has resulted in significant advancement in our conceptualisation and methodological consideration of scale and scaling (Wiens 1989). Unsurprisingly, many of the research questions formulated by academic scientists, such as presented here, acknowledge the importance of scale. Explicit consideration of scale effects, the recognition of multi-scale drivers, cross-scale coupling, and scale-dependency offers great promise for advancing effective management actions. At the organism level, species, and individuals within them, can respond to environmental heterogeneity in contrasting ways and at different scales (Kotliar \& Wiens 1990, McGarigal et al. 2016). If we accept this organismcentric or process-focussed view in seascape ecology, then our framing of research questions and design of methodology, particularly scale selection, must be anchored to scales that are ecologically meaningful to the focal organism, community, or process. Often, a focal scale can be defined by an ecological process such as an organism's movement patterns (Wiens \& Milne 1989, Pittman \& McAlpine 2003). For practical purposes, a spatial continuum of complex patterns is often handled through the concept of spatial hierarchies with multiple focal levels (Kotliar \& Wiens 1990). Like landscape ecology, seascape ecology contends with large and diverse datasets across a wide array of spatial and temporal scales and can integrate information derived from reductionist and holistic science.

Scale awareness and seascape ecology thinking have direct implications for the design of multi-scale spatial management solutions that facilitate crossscale management and minimise scale mismatches (Lagabrielle et al. 2018).

\subsubsection{Theme 7: Seascape goods and services}

The highest-priority research question in the theme of seascape goods and services was Q9, ranked seventh by academic scientists and sixth by practitioners. This question received an equal proportion of votes $(29 \%)$ by both groups. Q45 was the highest priority for practitioners (ranked fifth), but it was only ranked $15^{\text {th }}$ by academic scientists, highlighting a substantial divergence of agreement between the 2 groups for this question.

Q9: Which seascape types provide maximum benefits in terms of biodiversity and productivity, support optimal functional connectivity, and how will these functions change through re-structuring processes resulting in habitat loss and fragmentation?

Q45: What methods are most effective for linking spatial characteristics of the seascape to social, cultural, and ecosystem service values that are meaningful to management practitioners and communities?

Research challenges. Understanding how seascape structure, composition, and spatial configuration affect the quality, productivity, and rate of flow and delivery of ecosystem services is critical for natural capital accounting and designing restorative and sustainable development strategies. For example, in tropical coastal areas, recognition of synergistic interactions among adjacent patches of mangrove, seagrass, and coral reefs has led to a conceptual shift from a single patch to patch mosaics in the characterisation of ecosystem services (Moberg \& Folke 1999, Moberg \& Rönnbäck 2003, Harborne et al. 2006). This approach acknowledges that the whole interconnected system contributes to ecosystem services (Fig. 6), such that the combined spatial configuration of coral reefs, seagrass, and mangroves enhances coastal protection from waves and storms whilst also influencing coastal resilience (Guannel et al. 2016). Likewise, horizontal and vertical connectivity and structural heterogeneity mediate the flow of ecosystem services in the deep sea (Townsend et al. 2018, Turner et al. 2019), and sea surface productivity fronts have been considered to form 'hotspots of ecosystem services' in the pelagic ocean (Martinetto et al. 2020). Economic models have also begun to consider the influence of seascape configuration on ecosystem services and the cost-benefits associated with human modifications to the configuration (Sanchirico \& Springborn 2011, Barbier \& Lee 2014). Mapping of ecosystem service rarely considers the $4 \mathrm{Cs}$, yet this new 'seascape economics' perspective, with a focus on how goods and services are generated through ecological connectivity, has the potential to transform marine natural capital accounting (Arkema et al. 2017, Barbier 2018). Determining the metrics of interest and appropriately interpreting information to inform the management of ecosystem services presents a complex challenge that will benefit from interdisciplinary col- 


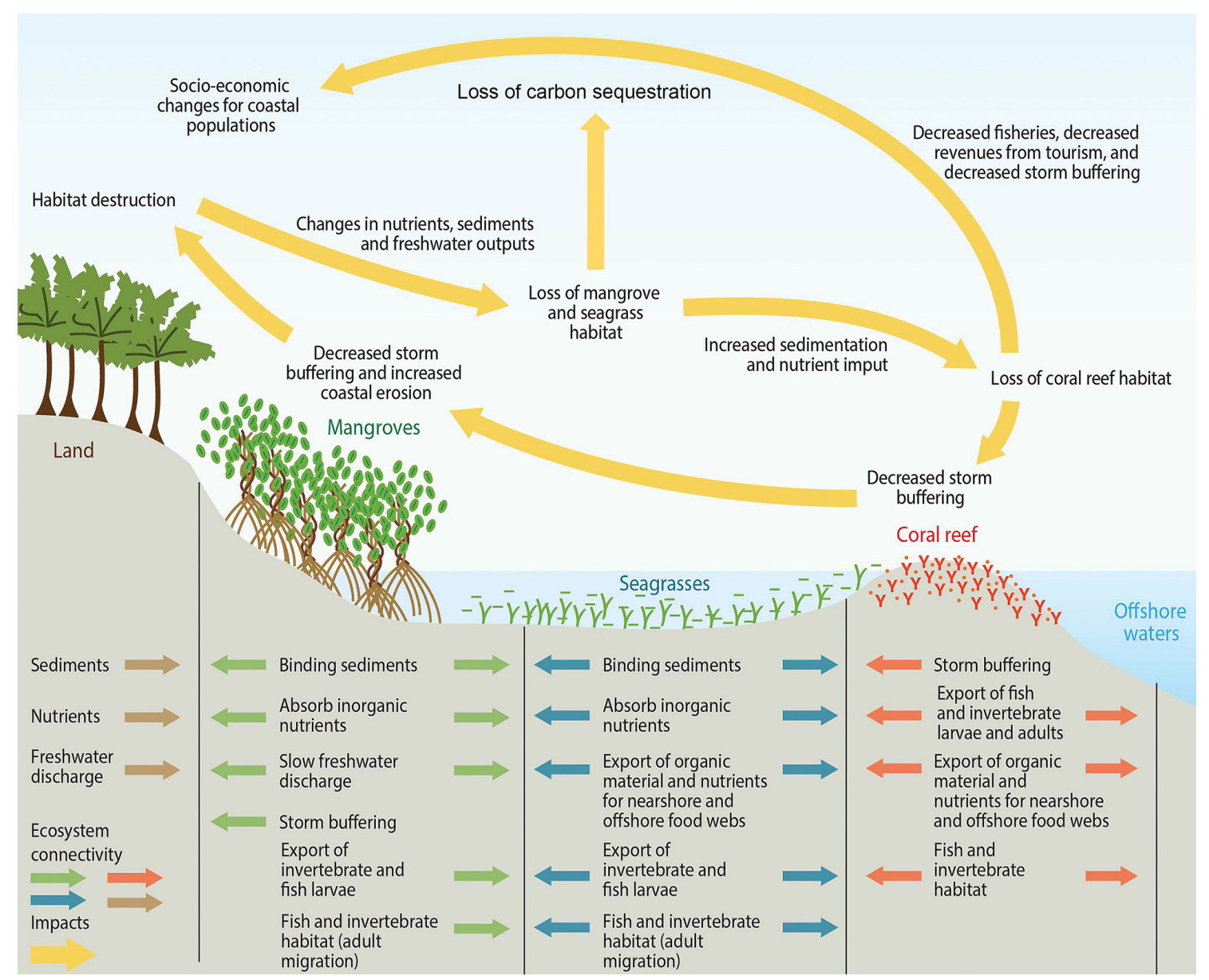

Fig. 6. Example of seascape connectivity among different patch types in a tropical seascape and the flow of ecosystem services. Ecological linkages are depicted by arrows: terrestrial (brown); mangroves (green); seagrasses (blue); and coral reefs

(red). Potential feedbacks from human impacts are also shown (yellow arrows) (adapted from Silvestri \& Kershaw 2010)

laborations among bioeconomists, social scientists, and ecologists.

Application. A key premise in landscape ecology is that ecological function, and hence ecosystem services, will vary with the spatial configuration of habitat patches. Integrating seascape ecology concepts and tools into ecological economics will add realism to valuations and help to understand the consequences of disruptions to seascape structure and functional connectivity (Barbier 2018). For example, the spatial arrangement of habitat patches is now acknowledged as a factor in the flow, trapping, and sequestration of organic carbon, but rarely considered in blue carbon accounting or strategies to enhance carbon capture (Gullström et al. 2018, Huxham et al. 2018, Fan et al. 2020, Asplund et al. 2021). Mapping, measuring, and valuing ecosystem services across the seascape will provide new bioeconomic, management, and policy insights with impor- tant implications for targeted management actions (Spake et al. 2019). With special attention to the $4 \mathrm{Cs}$, seascape ecology can help identify, characterise, and assess vulnerabilities and threats to provisioning and regulatory functions at scales that are relevant to decision making. In addition, the range of spatial pattern metrics has broadened to include social landscape metrics to map and quantify important areas for ecosystem service assessments yet have only been applied on terrestrial landscapes (De Vreese et al. 2016). A more holistic seascape ecology that accounts for a broad spectrum of cultural and intrinsic values will be important, since narrow socioeconomic values alone can undervalue culturally important ocean spaces (Hamel et al. 2018). Modelling and mapping of the spatial dynamics of marine ecosystem service flows currently lag behind progress in terrestrial systems, thereby presenting a knowledgesharing opportunity on methodological solutions and 
lessons learned. A new holistic seascape framework that integrates the $4 \mathrm{Cs}$ for ecosystem services valuation will require the application and evaluation of a wide range of tropical and temperate seascapes.

\subsubsection{Theme 8: Pelagic seascapes}

The highest-priority research question in the theme of pelagic seascapes was Q20, ranked tenth by both academic scientists and practitioners. With $23 \%$ of votes, this question was placed in the medium-priority tier. The coastal research bias in seascape ecology and in marine management in both respondent groups is likely the reason for very few questions in this theme.

Q20: What combination of survey and analytical techniques is most appropriate for characterising pelagic seascapes?

Research challenges. Concern is growing over human impacts across the pelagic ocean, particularly as it remains one of the least understood and most challenging environments for research and management (Dickey-Collas et al. 2017, Ortuño Crespo et al. 2020). Advances in ocean observing systems and spatial hydrodynamic modelling since the 1970s have enabled us to map, classify, and track dynamic spatial structure in the form of eddies, water surface roughness, currents, runoff plumes, ice cover, temperature fronts, and plankton patches that are detectable at the ocean surface (Steele 1989, Scales et al. 2014, Kavanaugh et al. 2016) (Fig. 1). Subsurface structures such as internal waves, thermoclines, haloclines, or boundary layers are increasingly being mapped and modelled in multiple dimensions (Ryan et al. 2005, Sayre et al. 2017). These technological advances are enabling the application of seascape ecology techniques, including novel spatial metrics, to pelagic waters (Miller 2009, Alvarez-Berastegui et al. 2016) and the deep seafloor (Bouchet et al. 2015). Significant research challenges exist for the application of seascape ecology to the pelagic ocean, which will require technological and conceptual innovation and integration with oceanography (Hidalgo et al. 2016, Lowerre-Barbieri et al. 2019).

Application. With the integration of satellite data, ocean sensors, animal telemetry, and geospatial modelling, studies of pelagic seascapes have demonstrated that dynamic geometric features (patches, boundaries, gradients) of the ocean can be geographically persistent and can help explain ecological processes such as animal migrations and foraging behaviour (Alvarez-Berastegui et al. 2014,
Scales et al. 2014, Hidalgo et al. 2016, Luo et al. 2020). The inclusion of the vertical dimension of pelagic seascapes in animal tracking studies is now generating new insights into mechanistic linkages between physical processes and marine predator behaviour, extending conservation prioritisation vertically (Venegas-Li et al. 2018, Braun et al. 2019). Dynamic ocean management tools that integrate ecological connectivity already support systematic conservation planning in the high seas (Dunn et al. 2016). Hierarchical, multi-dimensional biogeographic frameworks that incorporate ocean dynamics are being advanced for pelagic seascapes based on landscape ecology theory, revealing new insights on species-seascape relationships (Kavanaugh et al. 2014, Hidalgo et al. 2016, Scales et al. 2018). As pelagic seascapes change and species shift in response to thermal stress, changes in ocean circulation, biological invasions, ocean acidification, and hypoxia, a major focal area for research will be to test if, and how, ecological theory and conservation practices shaped by landscape ecology can be applied to the open ocean to better inform the design of effective conservation measures.

\subsubsection{Theme 9: Emerging technologies and metrics}

The highest-priority research question in the theme of emerging technologies and metrics was Q6, ranked fifth by academic scientists and first by practitioners. This places Q6 in the highest-priority tier, highlighting the importance of reliable quantitative tools for practitioners and the importance of considering scale.

Q6: What are the most useful metrics and indicators for characterising and monitoring spatiotemporal patterns in seascapes, and over what scales should these be measured?

Research challenges. There is an increasing need for reliable and meaningful metrics capable of measuring progress towards policy targets and tracking environmental change (Andries et al. 2019). Policy indicators will need to be able to measure and visualise the outcome(s) of the policy action(s) efficiently. Sustainable planning indicators need to be applicable tools that help design and assess plans. A significant challenge exists for both science and management to develop spatial metrics and indicators that are both ecologically and operationally relevant, going beyond simple area metrics for tracking habitat losses or gains. Where habitat is altered, or removed, the change in spatial pattern and the cas- 
cading changes to function are often overlooked. Spatial pattern metrics (2D and 3D) provide an opportunity for the development of indicators with sufficient sensitivity to give early warning of impending tipping points and ecosystem regime shifts in the ocean. Discovering which metrics can be used as indicators for management is an important challenge that will involve careful evaluation in different environments. The pelagic ocean will likely require the development of new metrics for dynamic fluid seascapes. Sharing of existing time series data (e.g. BioTIME; Dornelas et al. 2018) and new sensors capable of mapping a wider range of variables at greater spatial and temporal resolution will support a diversification of applications for seascape ecology. For example, innovations such as marine laser altimetry and multispectral multibeam sonar have significantly improved the mapping of complex abiotic and biotic patterns across the seafloor (Collin et al. 2018, Brown et al. 2019). Additional challenges will include the development and evaluation of metrics and indicators that capture holistic system properties and dynamic complexity, including socioecological conditions to inform sustainable development and resilience-based management. Advances in the speed of acquisition and processing of remotely sensed data combined with artificial intelligence (geoAI) algorithms (machine learning and deep learning) for image analyses, data integration, and spatial prediction will likely also lead to new spatial pattern metrics and indicators for ocean monitoring and reporting (Humphries \& Huettmann 2018a, Sun \& Scanlon 2019, Sagi et al. 2020). Improved access to marine data, including crowdsourced geospatial and citizen science data, and cloud-based platforms for rapid processing of complex geographical data will improve the capacity to deliver near-real-time insights for adaptive marine management (Humphries \& Huettmann 2018b). The development of 'digital twins' of the Earth will expand the opportunities for virtual experiments in seascape ecology to explore complex scenarios of dynamic pattern-process linkages (Bauer et al. 2021).

Application. Landscape ecology and other disciplines such as geomorphometry and surface metrology in industrial engineering have developed a variety of spatial pattern metrics suitable for measuring 2- and 3-dimensional properties of surface composition and configuration (Wedding et al. 2011, Bouchet et al. 2015, Lecours et al. 2016, Frazier \& Kedron 2017). Spatial pattern metrics and indicators will help quantify, characterise, interpret, and communicate pattern-pattern and pattern-process relationships and enhance change detection and spatial modelling (Gustafson 2019, Lacharité \& Brown 2019). With a focus on quantifying spatial patterns at multiple scales, seascape ecology has expanded the range of ecologically meaningful patterns and the diversity of explanatory variables in marine ecology (Wedding et al. 2011). Spatial pattern metrics vary in their relevance to specific ecological processes, but where a strong link is evident, changes in metric values can be indicative of ecological condition and the ability of seascapes to provide ecosystem services (Santos et al. 2016, Scales et al. 2018). Seascape ecologists use suites of metrics/indicators applied to different representations of seascape heterogeneity (patch mosaics, terrains, water volumes) that must be applied with an understanding of scale effects and associated uncertainty in the link to processes (Wedding et al. 2011). Novel pattern metrics with special relevance to practitioners may need to be developed and tested through a transdisciplinary co-production process to ensure they are operationally relevant for management (Nassauer \& Opdam 2008). Further work is required into the selection of metrics, their ecological relevance for marine ecosystems, and the evaluation of scale effects and error propagation, with much to gain from lessons learned and best practice in applications to terrestrial landscape planning (Frazier \& Kedron 2017, Gustafson 2019). In addition, seascape ecology has yet to make good use of emerging genetic techniques such as environmental DNA, where spatial and temporal patterns in species and biodiversity could be linked to the $4 \mathrm{Cs}$ to advance a patternoriented seascape genomics (Grummer et al. 2019).

\section{CONCLUSION}

We have presented and ranked research priorities to advance the field of seascape ecology and scanned the horizon to explore seascape ecology as an emerging solution-oriented ecological science. The diverse range of applied research questions and themes listed here also serves to illustrate the broad interdisciplinary scope of seascape ecology. By taking landscape ecology to the sea, seascape ecology offers an integrative multi-scale framework with concepts, techniques, and tools that broaden the range of variables beyond the conventional ecological toolkit, with potential for new ecological insights across a range of scales.

To emerge as a transformative science capable of helping society better protect, restore, and advance sustainable living, the seascape ecology paradigm will need to be extended and evolve into a more com- 
prehensive solution-oriented science, as have sectors of landscape ecology (Wu 2006, 2013, Opdam et al. 2018). Seascape ecologists will need to span academic and practitioner boundaries, understand the operational opportunities and constraints of marine management practice, share knowledge, make code and data more easily available, and seek out opportunities for transdisciplinary research (Keeler et al. 2017, Safford et al. 2017). By 'transdisciplinary', we mean research that has both interactions across disciplines and participation from relevant non-academic sectors of society. Further collaborative research prioritisation efforts with greater dialogue between academic scientists and management practitioners are required to co-formulate research questions and $\mathrm{co}-$ develop projects that demonstrate the application of seascape ecology (Cvitanovic et al. 2016, Dey et al. 2020, Fisher et al. 2020).

Development of a holistic seascape ecology framework that considers the full range of factors connecting people and the sea within a coupled socioecological system is required (Pittman et al. 2018). The development of a more holistic transdisciplinary and multiple scale approach in seascape ecology is consistent with addressing the sustainable development goals (SDGs) identified by the UN 2030 Agenda for Sustainable Development. The reach of seascape ecology extends beyond SDG14 'Life Below Water' (Rees et al. 2018b) and recognises the interlinkages among SDGs, particularly those related to food security, energy, sustainable living, and climate change (i.e. multi-SDG nexus), where a spatially explicit and integrative multi-scale systems approach can form a useful framework for a sustainability science (Liu et al. 2015). The conceptual and operational shift to a seascape ecology approach has generated a wide range of new and fundamental questions in ecology, where explicit consideration of the $4 \mathrm{Cs}$ (context, configuration, connectivity, and consideration of scale) is of critical importance to efforts to restore and support a thriving ocean.

Acknowledgements. We are grateful to the many practitioner respondents for the time taken to engage with our questionnaire. K.L.Y. was funded by a NERC Knowledge Exchange Fellowship NE/P00668X/1. We thank R. M. Starr and 2 anonymous reviewers, who provided comments that helped improve the manuscript.

\section{LITERATURE CITED}

Albert CH, Yoccoz NG, Edwards TC Jr, Graham CH, Zimmermann NE, Thuiller W (2010) Sampling in ecology and evolution - bridging the gap between theory and practice. Ecography 33:1028-1037
Alexander KA, Hobday AJ, Cvitanovic C, Ogier E and others (2019) Progress in integrating natural and social science in marine ecosystem-based management research. Mar Freshw Res 70:71-83

* Alvarez-Berastegui D, Ciannelli L, Aparicio-Gonzalez A, Reglero P and others (2014) Spatial scale, means and gradients of hydrographic variables define pelagic seascapes of bluefin and bullet tuna spawning distribution. PLOS ONE 9:e109338

* Alvarez-Berastegui D, Hidalgo M, Tugores MP, Reglero P and others (2016) Pelagic seascape ecology for operational fisheries oceanography: modelling and predicting spawning distribution of Atlantic bluefin tuna in Western Mediterranean. ICES J Mar Sci 73:1851-1862

Andries A, Morse S, Murphy R, Lynch J, Woolliams E, Fonweban J (2019) Translation of Earth observation data into sustainable development indicators: an analytical framework. J Sustain Dev 27:366-376

Arkema KK, Griffin R, Maldonado S, Silver J, Suckale J, Guerry AD (2017) Linking social, ecological and physical science to advance natural and nature-based protection for coastal communities. Ann N Y Acad Sci 1399:5-26

Asplund ME, Dahl M, Ismail RO, Arias-Ortiz A and others (2021) Dynamics and fate of blue carbon in a mangroveseagrass seascape: influence of landscape configuration and land-use change. Landsc Ecol (in press), https://doi. org/10.1007/s10980-021-01216-8

Babí Almenar J, Rugani B, Geneletti D, Brewer T (2018) Integration of ecosystem services into a conceptual spatial planning framework based on a landscape ecology perspective. Landsc Ecol 33:2047-2059

Balbar AC, Metaxas A (2019) The current application of ecological connectivity in the design of marine protected areas. Glob Ecol Conserv 17:e00569

*Barbier EB (2017) Marine ecosystem services. Curr Biol 27: R507-R510

Barbier EB (2018) Seascape economics: valuing ecosystem services across the seascape. In: Pittman SJ (ed) Seascape ecology. Wiley \& Sons, Hoboken, NJ, p 465-481

*Barbier EB, Lee KD (2014) Economics of the marine seascape. Int Rev Environ Resour Econ 7:35-65

Bauer P, Stevens B, Hazeleger W (2021) A digital twin of Earth for the green transition. Nat Clim Change 11:8083

Bax NJ, Miloslavich P, Muller-Karger FE, Allain V and others (2019) A response to scientific and societal needs for marine biological observations. Front Mar Sci 6:395

* Bayraktarov E, Saunders MI, Abdullah S, Mills M and others (2016) The cost and feasibility of marine coastal restoration. Ecol Appl 26:1055-1074

Beger M, Grantham HS, Pressey RL, Wilson KA and others (2010) Conservation planning for connectivity across marine, freshwater, and terrestrial realms. Biol Conserv 143:565-575

Bell SS, Furman BT (2017) Seascapes are landscapes after all; comment on Manderson (2016): Seascapes are not landscapes: an analysis performed using Bernhard Riemann's rules. ICES J Mar Sci 73:1831-1838

Bell SS, McCoy ED, Mushinsky HR (eds) (1991) Habitat structure: the physical arrangement of objects in space. Springer Science \& Business Media, Dordrecht

Bell SS, Fonseca MS, Motten LB (1997) Linking restoration and landscape ecology. Restor Ecol 5:318-323

* Bennett NJ (2018) Navigating a just and inclusive path towards sustainable oceans. Mar Policy 97:139-146 
Berkström C, Eggertsen L, Goodell W, Cordeiro CAMM and others (2020) Thresholds in seascape connectivity: The spatial arrangement of nursery habitats structure [sic] fish communities on nearby reefs. Ecography 43:882-896

Birkeland C (1985) Ecological interactions between mangroves, seagrass beds, and coral reefs. Ecological interactions between tropical coastal ecosystems. UNEP Regional Seas Rep 73. United Nations Environment Program, Nairobi

Bishop MJ, Mayer-Pinto M, Airoldi L, Firth LB and others (2017) Effects of ocean sprawl on ecological connectivity: impacts and solutions. J Exp Mar Biol Ecol 492:7-30

Borja A, Andersen JH, Arvanitidis CD, Basset A and others (2020) Past and future grand challenges in marine ecosystem ecology. Front Mar Sci 7:362

Bormann FH, Likens GE (eds) (1979) Pattern and process of a forested system. Springer-Verlag, New York, NY

* Boström C, Pittman SJ, Simenstad C, Kneib RT (2011) Seascape ecology of coastal biogenic habitats: advances, gaps, and challenges. Mar Ecol Prog Ser 427:191-217

Bouchet PJ, Meeuwig JJ, Salgado Kent CP, Letessier TB, Jenner CK (2015) Topographic determinants of mobile vertebrate predator hotspots: current knowledge and future directions. Biol Rev Camb Philos Soc 90:699-728

Bradley M, Nagelkerken I, Baker R, Sheaves M (2020) Context dependence: a conceptual approach for understanding the habitat relationships of coastal marine fauna. BioScience 70:986-1004

Braun CD, Gaube P, Sinclair-Taylor TH, Skomal GB, Thorrold SR (2019) Mesoscale eddies release pelagic sharks from thermal constraints to foraging in the ocean twilight zone. Proc Natl Acad Sci USA 116:17187-17192

Brodie S, Jacox MG, Bograd SJ, Welch H and others (2018) Integrating dynamic subsurface habitat metrics into species distribution models. Front Mar Sci 5:219

Browder JA, Bartley HA, Davis KS (1985) A probabilistic model of the relationship between marshland-water interface and marsh disintegration. Ecol Model 29: 245-260

* Brown CJ, Smith SJ, Lawton P, Anderson JT (2011) Benthic habitat mapping: a review of progress towards improved understanding of the spatial ecology of the seafloor using acoustic techniques. Estuar Coast Shelf Sci 92:502-520

* Brown CJ, Beaudoin J, Brissette M, Gazzola V (2019) Multispectral multibeam echo sounder backscatter as a tool for improved seafloor characterization. Geosciences 9:126

Brudvig LA, Barak RS, Bauer JT, Caughlin TT and others (2017) Interpreting variation to advance predictive restoration science. J Appl Ecol 54:1018-1027

* Bryan-Brown DN, Connolly RM, Richards DR, Adame F, Friess DA, Brown CJ (2020) Global trends in mangrove forest fragmentation. Sci Rep 10:7117

Calabrese JM, Fagan WF (2004) A comparison-shopper's guide to connectivity metrics. Front Ecol Environ 2: 529-536

Caldwell IR, Gergel SE (2013) Thresholds in seascape connectivity: influence of mobility, habitat distribution, and current strength on fish movement. Landsc Ecol 28: 1937-1948

* Capotondi A, Jacox M, Bowler C, Kavanaugh M and others (2019) Observational needs supporting marine ecosystems modeling and forecasting: from the global ocean to regional and coastal systems. Front Mar Sci 6:623

Carr MH, Robinson SP, Wahle C, Davis G and others (2017)
The central importance of ecological spatial connectivity to effective coastal marine protected areas and to meeting the challenges of climate change in the marine environment. Aquat Conserv 27:6-29

Cattano C, Agostini S, Harvey BP, Wada S and others (2020) Changes in fish communities due to benthic habitat shifts under ocean acidification conditions. Sci Total Environ 725:138501

* Choi YD, Temperton VM, Allen EB, Grootjans AP and others (2008) Ecological restoration for future sustainability in a changing environment. Ecoscience 15:53-64

* Claudet J, Bopp L, Cheung WW, Devillers R and others (2020) A roadmap for using the UN Decade of Ocean Science for Sustainable Development in support of science, policy, and action. One Earth 2:34-42

* Cogan CB, Todd BJ, Lawton P, Noji TT (2009) The role of marine habitat mapping in ecosystem-based management. ICES J Mar Sci 66:2033-2042

Colbo K, Ross T, Brown C, Weber T (2014) A review of oceanographic applications of water column data from multibeam echosounders. Estuar Coast Shelf Sci 145:41-56

* Collin A, Ramambason C, Pastol Y, Casella E and others (2018) Very high resolution mapping of coral reef state using airborne bathymetric LiDAR surface-intensity and drone imagery. Int J Remote Sens 39:5676-5688

Connolly RM, Hindell JS (2006) Review of nekton patterns and ecological processes in seagrass landscapes. Estuar Coast Shelf Sci 68:433-444

Costa B, Taylor JC, Kracker L, Battista T, Pittman SJ (2014) Mapping reef fish and the seascape: using acoustics and spatial modeling to guide coastal management. PLOS ONE 9:e85555

Costanza R, Sklar FH, White ML (1990) Modeling coastal landscape dynamics. BioScience 40:91-107

* Crowder L, Norse E (2008) Essential ecological insights for marine ecosystem-based management and marine spatial planning. Mar Policy 32:772-778

* Cumming GS (2011) Spatial resilience: integrating landscape ecology, resilience, and sustainability. Landsc Ecol 26:899-909

* Cumming GS, Cumming DHM, Redman CL (2006) Scale mismatches in social-ecological systems: causes, consequences, and solutions. Ecol Soc 11:14

Cvitanovic C, Wilson SK, Fulton CJ, Almany GR and others (2013) Critical research needs for managing coral reef marine protected areas: perspectives of academics and managers. J Environ Manag 114:84-91

Cvitanovic C, McDonald J, Hobday AJ (2016) From science to action: principles for undertaking environmental research that enables knowledge exchange and evidence-based decision-making. J Environ Manag 183: 864-874

* D'Urban Jackson T, Williams GJ, Walker-Springett G, Davies AJ (2020) Three-dimensional digital mapping of ecosystems: a new era in spatial ecology. Proc R Soc B 287:20192383

Dajka JC, Woodhead AJ, Norström AV, Graham NAJ, Riechers M, Nyström M (2020) Red and green loops help uncover missing feedbacks in a coral reef social-ecological system. People Nature 2:608-618

* De Vreese R, Leys M, Fontaine CM, Dendoncker N (2016) Social mapping of perceived ecosystem services supply the role of social landscape metrics and social hotspots for integrated ecosystem services assessment, landscape planning and management. Ecol Indic 66:517-533 
Demšar U, Long JA (2019) Potential path volume (PPV): a geometric estimator for space use in 3D. Mov Ecol 7:14

Dey CJ, Rego AI, Midwood JD, Koops MA (2020) A review and meta-analysis of collaborative research prioritization studies in ecology, biodiversity conservation and environmental science. Proc R Soc B 287:20200012

Dickey-Collas M, McQuatters-Gollop A, Bresnan E, Kraberg AC and others (2017) Pelagic habitat: exploring the concept of good environmental status. ICES J Mar Sci 74: 2333-2341

Dornelas M, Antão LH, Moyes F, Bates AE and others (2018) BioTIME: a database of biodiversity time series for the Anthropocene. Glob Ecol Biogeogr 27:760-786

* Drescher M, Perera AH, Johnson CJ, Buse LJ, Drew CA, Burgman MA (2013) Toward rigorous use of expert knowledge in ecological research. Ecosphere 4:83

* Dreujou E, Carrier-Belleau C, Goldsmit J, Fiorentino D and others (2020) Holistic environmental approaches and Aichi Biodiversity Targets: accomplishments and perspectives for marine ecosystems. PeerJ 8:e8171

Wuarte CM, Agusti S, Barbier E, Britten GL and others (2020) Rebuilding marine life. Nature 580:39-51

* Dunn DC, Maxwell SM, Boustany AM, Halpin PN (2016) Dynamic ocean management increases the efficiency and efficacy of fisheries management. Proc Natl Acad Sci USA 113:668-673

* Dunn DC, Harrison AL, Curtice C, DeLand S and others (2019) The importance of migratory connectivity for global ocean policy. Proc R Soc B 286:20191472

Ellison AM, Felson AJ, Friess DA (2020) Mangrove rehabilitation and restoration as experimental adaptive management. Front Mar Sci 7:327

Engelhard SL, Huijbers CM, Stewart-Koster B, Olds AD, Schlacher TA, Connolly RM (2017) Prioritising seascape connectivity in conservation using network analysis. J Appl Ecol 54:1130-1141

*Fan B, Li Y, Pavao-Zuckerman M (2020) The dynamics of land-sea-scape carbon flow can reveal anthropogenic destruction and restoration of coastal carbon sequestration. Landsc Ecol (in press), https://doi.org/10.1007/s10980-02001148-9

Fernandez M, Yesson C, Gannier A, Miller PI, Azevedo JM (2017) The importance of temporal resolution for niche modelling in dynamic marine environments. J Biogeogr 44:2816-2827

Fisher JRB, Wood SA, Bradford MA, Kelsey TR (2020) Improving scientific impact: how to practice science that influences environmental policy and management. Conserv Sci Pract 2:e210

Foley MM, Halpern BS, Micheli F, Armsby MH and others (2010) Guiding ecological principles for marine spatial planning. Mar Policy 34:955-966

Fowler CW, Belgrano A, Casini M (2013) Holistic fisheries management: combining macroecology, ecology, and evolutionary biology. Mar Fish Rev 75:1-36

Frazier AE, Kedron P (2017) Landscape metrics: past progress and future directions. Curr Landsc Ecol Rep 2:63-72

*García-Charton JA, Pérez-Ruzafa A, Sánchez-Jerez P, Bayle-Sempere JT, Reñones O, Moreno D (2004) Multiscale spatial heterogeneity, habitat structure, and the effect of marine reserves on Western Mediterranean rocky reef fish assemblages. Mar Biol 144:161-182

Gilby BL, Olds AD, Peterson CH, Connolly RM and others (2018a) Maximizing the benefits of oyster reef restoration for finfish and their fisheries. Fish Fish 19:931-947
Gilby BL, Olds AD, Connolly RM, Henderson CJ, Schlacher TA (2018b) Spatial restoration ecology: placing restoration in a landscape context. Bioscience 68:1007-1019

* Gilby BL, Olds AD, Duncan CK, Ortodossi NL, Henderson CJ, Schlacher TA (2020a) Identifying restoration hotspots that deliver multiple ecological benefits. Restor Ecol 28:222-232

* Gilby BL, Weinstein MP, Baker R, Cebrian J and others (2020b) Human actions alter tidal marsh seascapes and the provision of ecosystem services. Estuaries Coasts (in press), https://doi.org/10.1007/s12237-020-00830-0

* Glaser M, Glaeser B (2014) Towards a framework for crossscale and multi-level analysis of coastal and marine social-ecological systems dynamics. Reg Environ Change 14:2039-2052

Griffiths JR, Kadin M, Nascimento FJ, Tamelander T (2017) The importance of benthic-pelagic coupling for marine ecosystem functioning in a changing world. Glob Change Biol 23:2179-2196

Grober-Dunsmore R, Pittman SJ, Caldow C, Kendall MS, Frazer TK (2009) A landscape ecology approach for the study of ecological connectivity across tropical marine seascapes. In: Nagelkerken I (ed) Ecological connectivity among tropical coastal ecosystems. Springer, Dordrecht, p 493-530

* Grummer JA, Beheregaray LB, Bernatchez L, Hand BK, Luikart G, Narum SR, Taylor EB (2019) Aquatic landscape genomics and environmental effects on genetic variation. Trends Ecol Evol 34:641-654

Kuannel G, Arkema K, Ruggiero P, Verutes G (2016) The power of three: coral reefs, seagrasses and mangroves protect coastal regions and increase their resilience. PLOS ONE 11:e0158094

*Guerrero AM, McAllister RR, Corcoran J, Wilson KA (2013) Scale mismatches, conservation planning, and the value of social-network analyses. Conserv Biol 27:35-44

Gullström M, Lyimo LD, Dahl M, Samuelsson GS (2018) Blue carbon storage in tropical seagrass meadows relates to carbonate stock dynamics, plant-sediment processes, and landscape context: insights from the western Indian Ocean. Ecosystems 21:551-566

Gustafson EJ (2019) How has the state-of-the-art for quantification of landscape pattern advanced in the twentyfirst century? Landsc Ecol 34:2065-2072

*Hallowell MR, Gambatese JA (2010) Qualitative research: application of the Delphi method to CEM research. J Constr Eng Manag 136:99-107

Halpern BS, Frazier M, Afflerbach J, Lowndes JS, Micheli F (2019) Recent pace of change in human impact on the world's ocean. Sci Rep 9:11609

*Hamel MA, Pressey RL, Evans LS, Andréfouët S (2018) The importance of fishing grounds as perceived by local communities can be undervalued by measures of socioeconomic cost used in conservation planning. Conserv Lett 11:e12352

*Harborne AR, Mumby PJ, Micheli F, Perry CT, Dahlgren CP, Holmes KE, Brumbaugh DR (2006) The functional value of Caribbean coral reef, seagrass and mangrove habitats to ecosystem processes. Adv Mar Biol 50:57-189

* Hattab T, Albouy C, Lasram FB, Somot S, Le Loc'h F, Leprieur F (2014) Towards a better understanding of potential impacts of climate change on marine species distribution: a multiscale modelling approach. Glob Ecol Biogeogr 23:1417-1429

*Hazen EL, Scales KL, Maxwell SM, Briscoe DK (2018) A dynamic ocean management tool to reduce bycatch and support sustainable fisheries. Sci Adv 4:eaar3001 
Hewitt JE, Thrush SF, Dayton PK, Bonsdorff E (2007) The effect of spatial and temporal heterogeneity on the design and analysis of empirical studies of scale-dependent systems. Am Nat 169:398-408

Hidalgo M, Secor DH, Browman HI (2016) Observing and managing seascapes: linking synoptic oceanography, ecological processes, and geospatial modelling. ICES J Mar Sci 73:1825-1830

Holling CS (1992) Cross-scale morphology, geometry, and dynamics of ecosystems. Ecol Monogr 62:447-502

Hovel KA, Regan HM (2008) Using an individual-based model to examine the roles of habitat fragmentation and behavior on predator-prey relationships in seagrass landscapes. Landsc Ecol 23:75-89

Hovel KA, Regan HM (2018) Using individual-based models to explore seascape ecology. In: Pittman SJ (ed) Seascape ecology. Wiley \& Sons, Hoboken, NJ, p 229-257

Huettmann F (2011) Serving the global village through public data sharing as a mandatory paradigm for seabird biologists and managers: why, what, how, and a call for an efficient action plan. Open Ornithol J 4:1-11

Huettmann F, Czech B (2006) The steady state economy for global shorebird and habitat conservation. Endang Species Res 2:89-92

Huettmann F, Diamond AW (2006) Large-scale effects on the spatial distribution of seabirds in the Northwest Atlantic. Landsc Ecol 21:1089-1108

Huettmann F, Artukhin Y, Gilg O, Humphries G (2011) Predictions of 27 Arctic pelagic seabird distributions using public environmental variables, assessed with colony data: a first digital IPY and GBIF open access synthesis platform. Mar Biodivers 41:141-179

Hughes TP, Carpenter S, Rockström J, Scheffer M, Walker B (2013) Multiscale regime shifts and planetary boundaries. Trends Ecol Evol 28:389-395

Humphries GR, Huettmann F (2018a) Machine learning in wildlife biology: algorithms, data issues and availability, workflows, citizen science, code sharing, metadata and a brief historical perspective. In: Humphries GR, Magness DR, Huettmann F (eds) Machine learning for ecology and sustainable natural resource management. Springer, Cham, p 3-26

Humphries GR, Huettmann F (2018b) A perspective on the future of machine learning: moving away from 'Business as Usual' and towards a holistic approach of global conservation. In: Humphries GR, Magness DR, Huettmann F (eds) Machine learning for ecology and sustainable natural resource management. Springer, Cham, p 411-430

Humphries GR, Magness DR, Huettmann F (eds) (2018) Machine learning for ecology and sustainable natural resource management. Springer, Cham

Huntington BE, Karnauskas M, Babcock EA, Lirman D (2010) Untangling natural seascape variation from marine reserve effects using a landscape approach. PLOS ONE 5:e12327

Huxham M, Whitlock D, Githaiga M, Dencer-Brown A (2018) Carbon in the coastal seascape: how interactions between mangrove forests, seagrass meadows and tidal marshes influence carbon storage. Curr For Rep 4:101-110

Irlandi EA, Crawford MK (1997) Habitat linkages: the effect of intertidal saltmarshes and adjacent subtidal habitats on abundance, movement, and growth of an estuarine fish. Oecologia 110:222-230

Jackson EL, Attrill MJ, Jones MB (2006) Habitat characteristics and spatial arrangement affecting the diversity of fish and decapod assemblages of seagrass (Zostera marina) beds around the coast of Jersey (English Channel). Estuar Coast Shelf Sci 68:421-432

Jonsson PR, Moksnes PO, Corell H, Bonsdorff E, Nilsson Jacobi M (2020) Ecological coherence of marine protected areas: new tools applied to the Baltic Sea network. Aquat Conserv 30:743-760

Jouffray JB, Blasiak R, Norström AV, Österblom H, Nyström $M(2020)$ The blue acceleration: the trajectory of human expansion into the ocean. One Earth 2:43-54

Kavanaugh MT, Hales B, Saraceno M, Spitz YH, White AE, Letelier RM (2014) Hierarchical and dynamic seascapes: a quantitative framework for scaling pelagic biogeochemistry and ecology. Prog Oceanogr 120:291-304

Kavanaugh MT, Oliver M, Chavez F, Letelier RM, Muller Karger F, Doney SC (2016) Quo vadimus: seascapes as a new vernacular for ocean monitoring, management and conservation. ICES J Mar Sci 73:1839-1850

Keeler BL, Chaplin-Kramer R, Guerry AD, Addison PF (2017) Society is ready for a new kind of science - is academia? Bioscience 67:591-592

Kelly M, Tuxen KA, Stralberg D (2011) Mapping changes to vegetation pattern in a restoring wetland: finding pattern metrics that are consistent across spatial scale and time. Ecol Indic 11:263-273

Kendall MS, Miller TJ, Pittman SJ (2011) Patterns of scaledependency and the influence of map resolution on the seascape ecology of reef fish. Mar Ecol Prog Ser 427: $259-274$

Kool JT, Moilanen A, Treml EA (2013) Population connectivity: recent advances and new perspectives. Landsc Ecol 28:165-185

Kotliar NB, Wiens JA (1990) Multiple scales of patchiness and patch structure: a hierarchical framework for the study of heterogeneity. Oikos 59:253-260

Kough AS, Paris CB, Behringer DC, Butler MJ IV (2015) Modelling the spread and connectivity of waterborne marine pathogens: the case of PaV1 in the Caribbean. ICES J Mar Sci 72(Suppl 1):i139-i146

*Lacharité M, Brown CJ (2019) Utilizing benthic habitat maps to inform biodiversity monitoring in marine protected areas. Aquat Conserv 29:938-951

* Lagabrielle E, Lombard AT, Harris JM, Livingstone TC (2018) Multi-scale multi-level marine spatial planning: a novel methodological approach applied in South Africa. PLOS ONE 13:e0192582

* Lauchlan SS, Nagelkerken I (2020) Species range shifts along multistressor mosaics in estuarine environments under future climate. Fish Fish 21:32-46

* Layton C, Coleman MA, Marzinelli EM, Steinberg PD and others (2020) Kelp forest restoration in Australia. Front Mar Sci 7:74

* Lechner AM, Rhodes JR (2016) Recent progress on spatial and thematic resolution in landscape ecology. Curr Landsc Ecol Rep 1:98-105

KLecours V (2017) On the use of maps and models in conservation and resource management (warning: results may vary). Front Mar Sci 4:288

Lecours V, Devillers R, Schneider DC, Lucieer VL, Brown CJ, Edinger EN (2015) Spatial scale and geographic context in benthic habitat mapping: review and future directions. Mar Ecol Prog Ser 535:259-284

* Lecours V, Dolan MFJ, Micallef A, Lucieer VL (2016) A review of marine geomorphometry, the quantitative study of the seafloor. Hydrol Earth Syst Sci 20:3207-3244 
Lester SE, Dubel AK, Hernán G, McHenry J, Rassweiler A (2020) Spatial planning principles for marine ecosystem restoration. Front Mar Sci 7:328

Levin SA (1992) The problem of pattern and scale in ecology: the Robert H. MacArthur award lecture. Ecology 73: 1943-1967

Levin SA, Lubchenco J (2008) Resilience, robustness, and marine ecosystem-based management. Bioscience 58:27-32

Liu J (2017) Integration across a metacoupled world. Ecol Soc 22:29

Liu J, Hull V, Batistella M, DeFries R and others (2013) Framing sustainability in a telecoupled world. Ecol Soc 18:26

Kiu J, Mooney H, Hull V, Davis SJ, Gaskell J and others (2015) Systems integration for global sustainability. Science 347:1258832

Lowe WH, Allendorf FW (2010) What can genetics tell us about population connectivity? Mol Ecol 19:3038-3051

*LLowerre-Barbieri SK, Kays R, Thorson JT, Wikelski M (2019) The ocean's movescape: fisheries management in the bio-logging decade (2018-2028). ICES J Mar Sci 76: 477-488

* Luo J, Ault JS, Ungar BT, Smith SG (2020) Migrations and movements of Atlantic tarpon revealed by two decades of satellite tagging. Fish Fish 21:290-318

MacArthur RH, Wilson EO (1967) The theory of island biogeography. Princeton University Press, Princeton, NJ

Martinetto P, Alemany D, Botto F, Mastrángelo M and others (2020) Linking the scientific knowledge on marine frontal systems with ecosystem services. Ambio 49: 541-556

Matta A, Serra M (2016) A geodesign approach for using spatial indicators in land-use planning. Civ Eng Archit 4: 183-192

Maxwell SM, Gjerde KM, Conners MG, Crowder LB (2020) Mobile protected areas for biodiversity on the high seas. Science 367:252-254

* McAlpine CA, Seabrook LM, Rhodes JR, Maron M and others (2010) Can a problem-solving approach strengthen landscape ecology's contribution to sustainable landscape planning? Landsc Ecol 25:1155-1168

McGarigal K, Tagil S, Cushman SA (2009) Surface metrics: an alternative to patch metrics for the quantification of landscape structure. Landsc Ecol 24:433-450

McGarigal K, Wan HY, Zeller KA, Timm BC, Cushman SA (2016) Multi-scale habitat selection modeling: a review and outlook. Landsc Ecol 31:1161-1175

McHenry J, Welch H, Lester SE, Saba V (2019) Projecting marine species range shifts from only temperature can mask climate vulnerability. Glob Change Biol 25: 4208-4221

McLeod KL, Lubchenco J, Palumbi SR, Rosenberg AA (2005) Scientific consensus statement on marine ecosystem-based management. https://marineplanning.org/wpcontent/uploads/2015/07/Consensusstatement.pdf

* McNeill SE, Fairweather PG (1993) Single large or several small marine reserves? An experimental approach with seagrass fauna. J Biogeogr 20:429-440

* Meehan MC, Ban NC, Devillers R, Singh GG, Claudet J (2020) How far have we come? A review of MPA network performance indicators in reaching qualitative elements of Aichi Target 11. Conserv Lett 13:e12746

Meentemeyer V (1989) Geographical perspectives of space, time, and scale. Landsc Ecol 3:163-173

Melo-Merino SM, Reyes-Bonilla H, Lira-Noriega A (2020) Ecological niche models and species distribution models in marine environments: a literature review and spatial analysis of evidence. Ecol Model 415:108837

Miller PI (2009) Composite front maps for improved visibility of dynamic sea-surface features on cloudy SeaWiFS and AVHRR data. J Mar Syst 78:327-336

Miller PI, Christodoulou S (2014) Frequent locations of oceanic fronts as an indicator of pelagic diversity: application to marine protected areas and renewables. Mar Policy 45:318-329

Milligan RJ, Scott EM, Jones DOB, Bett BJ and others (2020) Evidence for seasonal cycles in deep-sea fish abundances: a great migration in the deep SE Atlantic? J Anim Ecol 89:1593-1603

Misiuk B, Lecours V, Bell T (2018) A multiscale approach to mapping seabed sediments. PLOS ONE 13:e0193647

Moberg F, Folke C (1999) Ecological goods and services of coral reef ecosystems. Ecol Econ 29:215-233

Moberg F, Rönnbäck P (2003) Ecosystem services of the tropical seascape: interactions, substitutions and restoration. Ocean Coast Manag 46:27-46

Morley JW, Frölicher TL, Pinsky ML (2020) Characterizing uncertainty in climate impact projections: a case study with seven marine species on the North American continental shelf. ICES J Mar Sci 77:2118-2133

*Mumby PJ (2006) Connectivity of reef fish between mangroves and coral reefs: algorithms for the design of marine reserves at seascape scales. Biol Conserv 128: $215-222$

* Nagelkerken I, Sheaves M, Baker R, Connolly RM (2015) The seascape nursery: a novel spatial approach to identify and manage nurseries for coastal marine fauna. Fish Fish 16:362-371

Nassauer J, Opdam P (2008) Design in science: extending the landscape ecology paradigm. Landsc Ecol 23: $633-644$

Norström AV, Cvitanovic C, Löf MF, West S and others (2020) Principles for knowledge co-production in sustainability research. Nat Sustainabil 3:182-190

Ogden JC, Gladfelter EH (eds) (1983) Coral reefs, seagrass beds, and mangroves: their interaction in the coastal zones of the Caribbean. Report of a workshop held at West Indies Laboratory, St. Croix, US Virgin Islands, May 1982. Unesco Rep Mar Sci 23. Unesco, Paris

Olds AD, Connolly RM, Pitt KA, Maxwell PS (2012) Habitat connectivity improves reserve performance. Conserv Lett 5:56-63

Olds AD, Connolly RM, Pitt KA, Pittman SJ and others (2016) Quantifying the conservation value of seascape connectivity: a global synthesis. Glob Ecol Biogeogr 25: $3-15$

Oleson KLL, Falinski KA, Audas DM, Coccia-Schillo S, Groves P, Teneva L, Pittman SJ (2018) Linking landscape and seascape conditions: science, tools, and management. In: Pittman SJ (ed) Seascape ecology. Wiley \& Sons, Hoboken, NJ, p 319-364

Opdam P, Luque S, Nassauer J, Verburg PH, Wu J (2018) How can landscape ecology contribute to sustainability science? Landsc Ecol 33:1-7

* Ortuño Crespo G, Mossop J, Dunn D, Gjerde K and others (2020) Beyond static spatial management: scientific and legal considerations for dynamic management in the high seas. Mar Policy 122:104102

* Page CE, Leggat W, Heron SF, Choukroun SM, Lloyd J, Ainsworth TD (2019) Seeking resistance in coral reef ecosystems: the interplay of biophysical factors and 
bleaching resistance under a changing climate. BioEssays 41:1800226

Paine RT, Levin SA (1981) Intertidal landscapes: disturbance and the dynamics of pattern. Ecol Monogr 51:145-178

Papastamatiou YP, Watanabe YY, Demšar U, Leos-Barajas V and others (2018) Activity seascapes highlight central place foraging strategies in marine predators that never stop swimming. Mov Ecol 6:9

*Parrish JD (1989) Fish communities of interacting shallowwater habitats in tropical oceanic regions. Mar Ecol Prog Ser 58:143-160

Parrott L, Meyer WS (2012) Future landscapes: managing within complexity. Front Ecol Environ 10:382-389

*Parsons ECM, Baulch S, Bechshoft T, Bellazzi G and others (2015) Key research questions of global importance for cetacean conservation. Endang Species Res 27:113-118

* Pasher J, Mitchell SW, King DJ, Fahrig L, Smith AC, Lindsay KE (2013) Optimizing landscape selection for estimating relative effects of landscape variables on ecological responses. Landsc Ecol 28:371-383

Paulo D, Cunha AH, Boavida J, Serrão EA, Gonçalves EJ, Fonseca M (2019) Open coast seagrass restoration. Can we do it? Large scale seagrass transplants. Front Mar Sci 6:52

Pendleton LH, Beyer H, Estradivari, Grose SO and others (2019) Disrupting data sharing for a healthier ocean. ICES J Mar Sci 76:1415-1423

Perry D, Staveley TAB, Gullström M (2018) Habitat connectivity of fish in temperate shallow-water seascapes. Front Mar Sci 4:440

Pittman SJ (ed) (2018a) Seascape ecology. Wiley \& Sons, Hoboken, NJ

Pittman SJ (2018b) Introducing seascape ecology. In: Pittman SJ (ed) Seascape ecology. Wiley \& Sons, Hoboken, NJ, p 3-25

Pittman SJ, Brown KA (2011) Multi-scale approach for predicting fish species distributions across coral reef seascapes. PLOS ONE 6:e20583

Pittman SJ, Costa B (2010) Linking cetaceans to their environment: spatial data acquisition, digital processing and predictive modeling for marine spatial planning in the Northwest Atlantic. In: Cushman SA, Huettmann F (eds) Spatial complexity, informatics, and wildlife conservation. Springer, Tokyo p 387-408

Pittman SJ, McAlpine CA (2003) Movements of marine fish and decapod crustaceans: process, theory and application. Adv Mar Biol 44:205-294

Pittman SJ, McAlpine CA, Pittman KM (2004) Linking fish and prawns to their environment: a hierarchical landscape approach. Mar Ecol Prog Ser 283:233-254

Pittman SJ, Caldow C, Hile SD, Monaco ME (2007) Using seascape types to explain the spatial patterns of fish in the mangroves of SW Puerto Rico. Mar Ecol Prog Ser 348:273-284

* Pittman SJ, Monaco ME, Friedlander AM, Legare B and others (2014) Fish with chips: tracking reef fish movements to evaluate size and connectivity of Caribbean marine protected areas. PLOS ONE 9:e96028

Pittman SJ, Lepczyk CA, Wedding LM, Parrain C (2018) Advancing a holistic systems approach in applied seascape ecology. In: Pittman SJ (ed) Seascape ecology. Wiley \& Sons, Hoboken, NJ, p 367-389

Popova E, Vousden D, Sauer WHH, Mohammed EY and others (2019) Ecological connectivity between the areas beyond national jurisdiction and coastal waters: safe- guarding interests of coastal communities in developing countries. Mar Policy 104:90-102

* Proudfoot B, Devillers R, Brown C (2020) Integrating finescale seafloor mapping and spatial pattern metrics into marine conservation prioritization. Aquat Conserv 30: 1613-1625

*Puckett BJ, Eggleston DB (2016) Metapopulation dynamics guide marine reserve design: importance of connectivity, demographics, and stock enhancement. Ecosphere 7: e01322

Purkis SJ, Graham NA, Riegl BM (2008) Predictability of reef fish diversity and abundance using remote sensing data in Diego Garcia (Chagos Archipelago). Coral Reefs 27:167-178

Qiu J, Game ET, Tallis H, Olander LP and others (2018) Evidence-based causal chains for linking health, development, and conservation actions. Bioscience 68:182-193

* Ray GC (1991) Coastal-zone biodiversity patterns. Bioscience 41:490-498

Raya Rey A, Huettmann F (2020) Telecoupling analysis of the Patagonian Shelf: a new approach to study global seabird-fisheries interactions to achieve sustainability. J Nat Conserv 53:125748

Rees MJ, Knot NA, Neilson J, Linklater M, Osterloh I, Jordan A, Davis AR (2018) Accounting for habitat structural complexity improves the assessment of performance in no-take marine reserves. Biol Conserv 224:100-110

* Rees SE, Pittman SJ, Foster N, Langmead O and others (2018a) Bridging the divide: social-ecological coherence in marine protected area network design. Aquat Conserv 28:754-763

* Rees S, Foster N, Langmead O, Pittman SJ, Johnson D (2018b) Defining the qualitative elements of Aichi Biodiversity Target 11 with regard to the marine and coastal environment in order to strengthen global efforts for marine biodiversity conservation outlined in the United Nations Sustainable Development Goal 14. Mar Policy 93:241-250

* Rezek RJ, Furman BT, Jung RP, Hall MO, Bell SS (2019) Long-term performance of seagrass restoration projects in Florida, USA. Sci Rep 9:15514

Kobbins BD, Bell SS (1994) Seagrass landscapes: a terrestrial approach to the marine subtidal environment. Trends Ecol Evol 9:301-304

* Roberts CM, Andelman S, Branch G, Bustamante RH and others (2003) Ecological criteria for evaluating candidate sites for marine reserves. Ecol Appl 13(sp1):199-214

Ross RE, Howell KL (2013) Use of predictive habitat modelling to assess the distribution and extent of the current protection of 'listed' deep-sea habitats. Divers Distrib 19: 433-445

Ryan JP, Chavez FP, Bellingham JG (2005) Physical-biological coupling in Monterey Bay, California: topographic influences on phytoplankton ecology. Mar Ecol Prog Ser 287:23-32

Safford HD, Sawyer SC, Kocher SD, Hiers JK, Cross M (2017) Linking knowledge to action: the role of boundary spanners in translating ecology. Front Ecol Environ 15: 560-568

Sagi T, Lehahn Y, Bar K (2020) Artificial intelligence for ocean science data integration: current state, gaps, and way forward. Elementa Sci Anthrop 8:21

Sanchirico JN, Springborn M (2011) How to get there from here: ecological and economic dynamics of ecosystem service provision. Environ Resour Econ 48:243-267 
Sandel B, Smith AB (2009) Scale as a lurking factor: incorporating scale-dependence in experimental ecology. Oikos 118:1284-1291

KSantos RO, Lirman D, Pittman SJ (2016) Long-term spatial dynamics in vegetated seascapes: fragmentation and habitat loss in a human-impacted subtropical lagoon. Mar Ecol 37:200-214

Santos RO, Lirman D, Pittman SJ, Serafy JE (2018) Spatial patterns of seagrasses and salinity regimes interact to structure marine faunal assemblages in a subtropical bay. Mar Ecol Prog Ser 594:21-38

* Saunders MI, Brown CJ, Foley MM, Febria CM and others (2016) Human impacts on connectivity in marine and freshwater ecosystems assessed using graph theory: a review. Mar Freshw Res 67:277-290

Sayre RG, Wright DJ, Breyer SP, Butler KA and others (2017) A three-dimensional mapping of the ocean based on environmental data. Oceanography 30:90-103

Scales KL, Miller PI, Hawkes LA, Ingram SN, Sims DW, Votier SC (2014) On the front line: frontal zones as priority at-sea conservation areas for mobile marine vertebrates. J Appl Ecol 51:1575-1583

Scales KL, Alvarez-Berastegui D, Embling C, Ingram S (2018) Pelagic seascapes. In: Pittman SJ (ed) Seascape ecology. Wiley \& Sons, Hoboken, NJ, p 57-88

Schill SR, Raber GT, Roberts JJ, Treml EA, Brenner J, Halpin PN (2015) No reef is an island: integrating coral reef connectivity data into the design of regional-scale marine protected area networks. PLOS ONE 10: e0144199

Schneider DC (2001) The rise of the concept of scale in ecology: The concept of scale is evolving from verbal expression to quantitative expression. Bioscience 51: 545-553

Schneider DC (ed) (2009) Quantitative ecology: measurement, models and scaling. Academic Press, London

Schroeder RE (1987) Effects of patch reef size and isolation on coral reef fish recruitment. Bull Mar Sci 41:441-451

Selkoe KA, D'Aloia CC, Crandall ED, Iacchei M and others (2016) A decade of seascape genetics: contributions to basic and applied marine connectivity. Mar Ecol Prog Ser 554:1-19

Silvestri S, Kershaw F (eds) (2010) Framing the flow: innovative approaches to understand, protect and value ecosystem services across linked habitats. UNEP World Conservation Monitoring Centre, Cambridge

Simberloff DS, Wilson EO (1969) Experimental zoogeography of islands: the colonization of empty islands. Ecology 50:278-296

Simenstad C, Reed D, Ford M (2006) When is restoration not? Incorporating landscape-scale processes to restore self-sustaining ecosystems in coastal wetland restoration. Ecol Eng 26:27-39

Sleeman JC, Boggs GS, Radford BC, Kendrick GA (2005) Using agent-based models to aid reef restoration: enhancing coral cover and topographic complexity through the spatial arrangement of coral transplants. Restor Ecol 13:685-694

Snow J, Mann M (2013) Qualtrics survey software: handbook for research professionals. Qualtrics Labs, Seattle, WA

Spake R, Bellamy C, Graham LJ, Watts K and others (2019) An analytical framework for spatially targeted management of natural capital. Nat Sustain 2:90-97

Stamoulis KA, Delevaux JMS, Williams ID, Poti M and oth- ers (2018) Seascape models reveal places to focus coastal fisheries management. Ecol Appl 28:910-925

Staveley TAB, Perry D, Lindborg R, Gullström M (2017) Seascape structure and complexity influence temperate seagrass fish assemblage composition. Ecography 40:936-946

Steele JH (1978) Some comments on plankton patches. In: Steele JH (ed) Spatial pattern in plankton communities. Plenum Press, New York, NY, p 1-20

Steele JH (1989) The ocean 'landscape'. Landsc Ecol 3: 185-192

Stillman RA, Railsback SF, Giske J, Berger UTA, Grimm V (2015) Making predictions in a changing world: the benefits of individual-based ecology. Bioscience 65:140-150

* Sun AY, Scanlon BR (2019) How can Big Data and machine learning benefit environment and water management: a survey of methods, applications, and future directions. Environ Res Lett 14:073001

Sutherland WJ, Freckleton RP, Godfray HC, Beissinger SR and others (2013) Identification of 100 fundamental ecological questions. J Ecol 101:58-67

* Theuerkauf SJ, Eggleston DB, Puckett BJ (2019) Integrating ecosystem services considerations within a GIS-based, habitat suitability index for oyster restoration. PLOS ONE 14:e0210936

* Thrush SF, Schneider DC, Legendre P, Whitlach RB and others (1997) Scaling-up from experiments to complex ecological systems: Where to next? J Exp Mar Biol Ecol 216: 243-254

Townsend M, Davies K, Hanley N, Hewitt JE, Lundquist CJ, Lohrer AM (2018) The challenge of implementing the marine ecosystem service concept. Front Mar Sci 5:359

* Tracey JA, Sheppard J, Zhu J, Wei F, Swaisgood RR, Fisher RN (2014) Movement-based estimation and visualization of space use in 3D for wildlife ecology and conservation. PLOS ONE 9:e101205

Treml EA, Halpin PN (2012) Marine population connectivity identifies ecological neighbors for conservation planning in the Coral Triangle. Conserv Lett 5:441-449

* Treml EA, Ford JR, Black KP, Swearer SE (2015) Identifying the key biophysical drivers, connectivity outcomes, and metapopulation consequences of larval dispersal in the sea. Mov Ecol 3:17

Turner MG (1989) Landscape ecology: the effect of pattern on process. Annu Rev Ecol Syst 20:171-197

* Turner MG (2005) Landscape ecology: What is the state of the science? Annu Rev Ecol Evol Syst 36:319-344

* Turner PJ, Thaler AD, Freitag A, Collins PC (2019) Deep-sea hydrothermal vent ecosystem principles: identification of ecosystem processes, services and communication of value. Mar Policy 101:118-124

V Van Katwijk MM, Thorhaug A, Marbà N, Orth RJ and others (2016) Global analysis of seagrass restoration: the importance of large-scale planting. J Appl Ecol 53:567-578

*Venegas-Li R, Levin N, Possingham H, Kark S (2018) 3D spatial conservation prioritisation: accounting for depth in marine environments. Methods Ecol Evol 9:773-784

V Virtanen EA, Atte M, Markku V (2020) Marine connectivity in spatial conservation planning: analogues from the terrestrial realm. Landsc Ecol 35:1021-1034

* Waltham NJ, Burrows D, Wegscheidl C, Buelow C and others (2019) Lost floodplain wetland environments and efforts to restore connectivity, habitat, and water quality settings on the Great Barrier Reef. Front Mar Sci 6:71

WWaltham NJ, Elliott M, Lee SY, Lovelock C and others (2020) UN decade on ecosystem restoration 2021-2030-what 
chance for success in restoring coastal ecosystems? Front Mar Sci 7:71

Watson DM, Doerr VA, Banks SC, Driscoll DA, van der Ree R, Doerr ED, Sunnucks P (2017) Monitoring ecological consequences of efforts to restore landscape-scale connectivity. Biol Conserv 206:201-209

Wedding LM, Friedlander AM, McGranaghan M, Yost RS, Monaco ME (2008) Using bathymetric lidar to define nearshore benthic habitat complexity: implications for management of reef fish assemblages in Hawaii. Remote Sens Environ 112:4159-4165

Wedding LM, Lepczyk CA, Pittman SJ, Friedlander AM, Jorgensen S (2011) Quantifying seascape structure: Extending terrestrial spatial pattern metrics to the marine realm. Mar Ecol Prog Ser 427:219-232

Weeks R (2017) Incorporating seascape connectivity in conservation prioritisation. PLOS ONE 12:e0182396

Wei CL, Rowe GT, Escobar-Briones E, Boetius A and others (2010) Global patterns and predictions of seafloor biomass using random forests. PLOS ONE 5:e15323

Welch H, Hazen EL, Bograd SJ, Jacox MG and others (2019) Practical considerations for operationalizing dynamic management tools. J Appl Ecol 56:459-469

Wiens JA (1989) Spatial scaling in ecology. Funct Ecol 3: 385-397

Wiens JA (1999) The science and practice of landscape ecology. In: Klopatek JM, Gardner RH (eds) Landscape ecological analysis. Springer, New York, NY, p 371-383

Wiens JA, Milne BT (1989) Scaling of 'landscapes' in landscape ecology, or, landscape ecology from a beetle's perspective. Landsc Ecol 3:87-96

Wiens JA, Rotenberry JT, Van Horne B (1987) Habitat occupancy patterns of North American shrubsteppe birds: the effects of spatial scale. Oikos 48:132-147

Wiens JA, Stenseth NC, Van Horne B, Ims RA (1993) Eco- logical mechanisms and landscape ecology. Oikos 66: 369-380

Wölfl AC, Snaith H, Amirebrahimi S, Devey CW and others (2019) Seafloor mapping-the challenge of a truly global ocean bathymetry. Front Mar Sci 6:283

Wolkovich EM, Cook BI, McLauchlan KK, Davies TJ (2014) Temporal ecology in the Anthropocene. Ecol Lett 17: 1365-1379

Wu J (2006) Landscape ecology, cross-disciplinarity, and sustainability science. Landsc Ecol 21:1-4

Wu J (2013) Landscape sustainability science: ecosystem services and human well-being in changing landscapes. Landsc Ecol 28:999-1023

Wu W (2019) Accounting for spatial patterns in deriving sealevel rise thresholds for salt marsh stability: more than just total areas? Ecol Indic 103:260-271

* Yates KL, Bouchet PJ, Caley MJ, Mengersen K and others (2018) Outstanding challenges in the transferability of ecological models. Trends Ecol Evol 33:790-802

* Yates P, Ziegler P, Welsford D, Wotherspoon S, Burch P, Maschette D (2019) Distribution of Antarctic toothfish Dissostichus mawsoni along East Antarctica: environmental drivers and management implications. Fish Res 219:105338

*Yeager LA, Keller DA, Burns TR, Pool AS, Fodrie FJ (2016) Threshold effects of habitat fragmentation on fish diversity at landscapes scales. Ecology 97:2157-2166

Zajac RN, Lewis RS, Poppe LJ, Twichell DC, Vozarik J, DiGiacomo-Cohen ML (2000) Relationships among seafloor structure and benthic communities in Long Island Sound at regional and benthoscape scales. J Coast Res 16:627-640

Zurell D, Berger U, Cabral JS, Jeltsch F and others (2010) The virtual ecologist approach: simulating data and observers. Oikos 119:622-635

Appendix. Full list of author addresses

\section{S. J. Pittman ${ }^{1,2, *}$, K. L. Yates ${ }^{3}$, P. J. Bouchet ${ }^{4,5}$, D. Alvarez-Berastegui ${ }^{6}$, S. Andréfouët ${ }^{7}$, S. S. Bell ${ }^{8}$, C. Berkström ${ }^{9,10}$, C. Boström ${ }^{11}$, C. J. Brown ${ }^{12}$, R. M. Connolly ${ }^{13}$, R. Devillers ${ }^{14}$, D. Eggleston ${ }^{15}$, B. L. Gilby ${ }^{16}$, M. Gullström ${ }^{17}$, B. S. Halpern ${ }^{18,19}$, M. Hidalgo ${ }^{20}$, D. Holstein ${ }^{21}$, K. Hovel ${ }^{22}$, F. Huettmann ${ }^{23}$, E. L. Jackson ${ }^{24}$, W. R. James ${ }^{25}$, J. B. Kellner ${ }^{26}$, C. Y. $\operatorname{Kot}^{27}$, V. Lecours ${ }^{28}$, C. Lepczyk ${ }^{29}$, I. Nagelkerken ${ }^{30}$, J. Nelson ${ }^{21}$, A. D. Olds ${ }^{16}$, R. O. Santos ${ }^{31}$, K. L. Scales ${ }^{16}$, D. C. Schneider ${ }^{32}$, H. T. Schilling ${ }^{33,34}$, C. Simenstad ${ }^{35}$, I. M. Suthers ${ }^{33,34}$, E. A. Treml ${ }^{36}$, L. M. Wedding ${ }^{1}$, P. Yates $^{34,37}$, M. Young ${ }^{36}$}

${ }^{1}$ Oxford Seascape Ecology Lab, School of Geography and the Environment, University of Oxford, Oxford OX1 3QY, UK ${ }^{2}$ Project Seascape CIC, Plymouth, PL2 1RP, UK

${ }^{3}$ School of Science, Engineering \& Environment, University of Salford, Manchester, M5 4WT, UK ${ }^{4}$ School of Mathematics \& Statistics, University of St. Andrews, St. Andrews, Fife, KY16 9SS, UK

${ }^{5}$ Centre for Research into Ecological \& Environmental Modelling, University of St. Andrews, St. Andrews, Fife, KY16 9LZ, UK

${ }^{6}$ Balearic Islands Coastal Observing and Forecasting System, 07121 Palma de Mallorca, Mallorca, Spain

${ }^{7}$ Institut de Recherche pour le Développement, UMR 9220 ENTROPIE, (Université de la Réunion, IFREMER, Université de la Nouvelle-Calédonie, Centre National de la Recherche Scientifique), Nouméa, New-Caledonia ${ }^{8}$ Department of Integrative Biology, University of South Florida, Florida, FL 33620, USA 
${ }^{9}$ Department of Aquatic Resources, Institute of Coastal Research, Swedish University of Agricultural Sciences, Skolgatan 6, 74242 Öregrund, Sweden

${ }^{10}$ Department of Ecology, Environment and Plant Sciences (DEEP), Stockholm University, SE 106 91, Stockholm, Sweden

${ }^{11}$ Environmental and Marine Biology, Åbo Akademi University, Artillerigatan 6, 20520, Åbo, Finland

${ }^{12}$ Department of Oceanography, Dalhousie University, Halifax, Nova Scotia, B3H 4R2, Canada

${ }^{13}$ Australian Rivers Institute - Coast \& Estuaries, School of Environment and Science, Griffith University, Queensland, QLD 4222, Australia

${ }^{14}$ Institut de Recherche pour le Développement, UMR 228 ESPACE-DEV (Univ. Montpellier, IRD, Univ. Antilles, Univ. Guyane, Univ. Réunion), 34393 Montpellier, France

${ }^{15}$ Department of Marine, Earth, and Atmospheric Sciences, North Carolina State University, Raleigh, North Carolina, NC 27695, USA

${ }^{16}$ School of Science and Engineering, University of the Sunshine Coast, Maroochydore, Queensland 4558, Australia

${ }^{17}$ School of Natural Sciences, Technology and Environmental Studies, Södertörn University, 14189 Huddinge, Stockholm, Sweden

${ }^{18}$ National Center for Ecological Analysis and Synthesis, University of California, Santa Barbara, California, CA 93101, USA

${ }^{19}$ Bren School of Environmental Science and Management, University of California, Santa Barbara, California, CA 93106, USA

${ }^{20}$ Instituto Español de Oceanografía, Centre Oceanográfic de les Balears, Ecosystem Oceanography Group (GRECO), 07015 Palma de Mallorca, Mallorca, Spain

${ }^{21}$ Department of Oceanography and Coastal Sciences, Louisiana State University, Baton Rouge, Louisiana, LA 70803, USA

${ }^{22}$ Department of Biology, Coastal \& Marine Institute, San Diego State University, San Diego, California, CA 92101, USA

${ }^{23}$ EWHALE Lab, Institute of Arctic Biology, Biology \& Wildlife Department, University of Alaska Fairbanks, Fairbanks, Alaska, AK 99775, USA

${ }^{24}$ Coastal Marine Ecosystems Research Centre, Central Queensland University, Gladstone, Queensland, QLD 4680, Australia

${ }^{25}$ Department of Biology, University of Louisiana, Lafayette, Louisiana, LA 70504, USA

${ }^{26}$ International Council for the Exploration of the Sea (ICES), 1553 Copenhagen V, Denmark

${ }^{27}$ Marine Geospatial Ecology Lab, Nicholas School of the Environment, Duke University, Beaufort, North Carolina, NC 28516, USA

${ }^{28}$ Geomatics Program and Fisheries \& Aquatic Sciences Program, School of Forest Resources \& Conservation, University of Florida, Florida, FL 32611, USA

${ }^{29}$ School of Forestry and Wildlife Sciences, Auburn University, Auburn, Alabama, AL 36849, USA

${ }^{30}$ Southern Seas Ecology Laboratories, School of Biological Sciences and the Environment Institute, The University of Adelaide, South Australia, SA 5005, Australia

${ }^{31}$ Institute of Environment, Florida International University, Miami, Florida, FL33199, USA

${ }^{32}$ Department of Ocean Sciences, Memorial University of Newfoundland, Newfoundland, A1B 3X7, Canada

${ }^{33}$ School of Biological, Earth, and Environmental Sciences, University of New South Wales, Sydney, New South Wales, NSW 2052, Australia

${ }^{34}$ Sydney Institute of Marine Science, Mosman, New South Wales, NSW 2088, Australia

${ }^{35}$ School of Aquatic and Fishery Sciences, University of Washington, Seattle, Washington, WA 98195-5020, USA

${ }^{36}$ School of Life and Environmental Sciences, Centre for Integrative Ecology, Deakin University, Victoria, VIC 3216, Australia

${ }^{37}$ Present address: Marine and Freshwater Species Conservation, Biodiversity Conservation Division, Department of Agriculture, Water and the Environment, Canberra ACT 2601, Australia

Editorial responsibility: Myron Peck,

Den Burg, The Netherlands

Reviewed by: R. M. Starr and 2 anonymous referees
Submitted: September 12, 2020

Accepted: February 9, 2021

Proofs received from author(s): March 23, 2021 